\title{
COMERCIO DE CERÁMICA ROMANA EN CARMO: LA TERRA SIGILLATA
}

\section{ROMAN POTTERY TRADE AT CARMO: THE TERRA SIGILLATA}

por

\author{
JACOBO VÁZQUEZ PAZ
}

RESUMEN Este trabajo pretende mostrar los resultados obtenidos del estudio de la vajilla de mesa romana en Carmo. La clasificación tipológica de estos materiales posibilita el acercamiento a la realidad comercial de la ciudad durante el altoimperio.

\begin{abstract}
This work tries to show the results obtained from the study of Roman table crockery in Carmo. The typological classification of these materials allow us to get a closer view to this city's trading scene during the Early Empire.
\end{abstract}

Palabras claves Carmona, Comercio, Terra Sigillata.

Key words Carmona, Commerce, Terra Sigillata.

\section{INTRODUCCIÓN}

"Te aconsejo que no minusvalores en exceso una vajilla de Arretio: Pórsena era un exquisito por sus cacharros de barro etruscos." (Marcial XIV 98)

En los últimos tiempos, el conocimiento que poseemos sobre la Carmona prehistórica ${ }^{1}$, protohistórica ${ }^{2}$ e histórica ${ }^{3}$, se ha ido ampliando progresivamente ${ }^{4}$. Las distintas intervenciones

1. Recientemente ha sido publicada una revisión del estado actual de la investigación sobre la ocupación durante la Edad del Cobre en Carmona (Conlin 2003: 83-143).

2. A la larga tradición historiográfica que ha surgido en torno al yacimiento de Carmona desde finales del s. XIX, hay que añadir las excavaciones efectuadas en la necrópolis orientalizante de La Cruz del Negro (Amores y Fernández Cantos 2000: 157-163) y los resultados obtenidos en las Intervenciones Arqueológicas de Urgencia efectuadas en la Casa-Palacio Marqués de Saltillo (Belén et al. 1997) y en Diego Navarro 20 (solar recientemente excavado por lo que agradecemos a Juan Manuel Román Rodríguez la información al respecto, así como la consulta del informe preliminar

ISSN: 1133-4525 ISSN-e: 2255-3924 
arqueológicas efectuadas en los últimos años en la ciudad están permitiendo avanzar en el conocimiento del fenómeno de romanización que se produjo en la antigua Carmo $^{5}$ y que tiene un punto crucial entre el reinado de Augusto ${ }^{6}$. En el yacimiento arqueológico de Carmona el inicio de la distribución de Terra Sigillata ${ }^{7}$ Itálica, salvo posibles elementos aislados que de momento deben ser estimados como esporádicos, coincide con el estreno de lo que supondría la verdadera romanización de la ciudad, así como con la consolidación de la red de distribución de servicios de mesa durante época augustea (Vázquez 2002).

El inicio del proceso de producción de T.S. en la Península Itálica marca prácticamente el fin del período republicano y el inicio del Alto Imperio en lo que a nivel interprovincial se refiere. El nacimiento de esta nueva producción, y principalmente su importación a las provincias romanas, se origina en un momento clave, ya que el lento proceso de romanización que se había iniciado en el entorno del valle del Guadalquivir con la ocupación del territorio por el ejército romano en el 206 a. C, se había visto acelerado por los posteriores movimientos de tropas y personas que se ocasionaron como consecuencia de las guerras y conflictos entre cesarianos y pompeyanos, se activó con el periodo de calma que se produjo con el advenimiento al poder del joven Octaviano. La romanización de la zona se vio a su vez favorecida por toda una política territorial que provocó el asentamiento de colonos procedentes principalmente de la Península Itálica, por el cambio estatutario de determinados núcleos poblacionales y por la organización administrativa de la Bética en cuatro conventos jurídicos ${ }^{8}$.

y planimetría asociada), que están permitiendo profundizar en el conocimiento del urbanismo y la religiosidad en la Carmona Protohistórica.

3. El conocimiento que teníamos sobre la ciudad romana de Carmo, fue ampliamente incrementado en el año 1999 con la celebración del II $^{\circ}$ Congreso de Historia de Carmona, que trató prácticamente en exclusividad el periodo romano de la ciudad. Sin embargo, la esfera del comercio y distribución de cerámicas romanas altoimperiales no fue tratada debido a la falta de estudios concretos sobre el tema en cuestión. A excepción de los servicios de mesa de época romanorepublicana de barniz negro denominados "campaniense", que han sido estudiados por J. J. Ventura (Véase Ventura 2001: 321-337 y Ventura 1990, Tesis Doctoral inédita), el resto de especies cerámicas romanas y el sistema de distribución que provocó su adquisición por los antiguos carmonenses, ha sido en parte obviado por la investigación en aras de otras manifestaciones culturales. Es el caso de la edilicia monumental de Carmona (Jiménez 1989; Ojeda 2001: 159-187; Márquez 2001: 251-262), o de sus necrópolis (Bendala 1976; Belén 1983: 209-226).

4. Una evaluación del panorama arqueológico carmonense en los últimos quince años del s. XX puede verse en Belén y Lineros 2001:109-134.

5. El volumen de información procedente de las excavaciones efectuadas en Carmona ha sido publicado recientemente y ofrece unos porcentajes estadísticos en los cuales el periodo romano de la ciudad representa el 52\% (12\% republicano y $40 \%$ imperial) del total de la información documentada arqueológicamente; de este porcentaje (52\%) el 77,77\% corresponde a época altoimperial y el resto a momentos republicanos (Belén y Lineros 2001: 114, Fig. 5 y 6).

6. Durante el s. II a. C y gran parte del s. I a. C se continuó básicamente perpetuando la estructuración urbana, y las fábricas edilicias de carácter turdetano en Carmo. Las excavaciones arqueológicas están registrando que es en momentos correspondientes al período de Augusto cuando comienza a darse un cambio significativo en el urbanismo y se documentan las primeras fábricas típicamente romanas dentro del ámbito doméstico de la ciudad (Beltrán 2001: 135-158), mientras que en lo monumental, nuevos datos aportados recientemente han permitido fechar con precisión la construcción de la Puerta de Córdoba en Carmona entre fines del s. I a. C. y los primeros decenios del s. I d. C. (Ojeda 2001: 159-187). Para las remodelaciones de la Puerta de Sevilla en Carmona y la erección de un templo en su terraza superior durante época de Augusto, véase Jiménez 1989. Sobre los orígenes en el s. I a. C. de la necrópolis occidental de Carmona y su desarrollo durante el período imperial, véase Bendala 1976.

7. A partir de ahora T.S.

8. Véase Caballos 1986: 13-26; Caballos 1990 y Chic 1997. Un acercamiento al análisis del proceso de romanización en Carmo, en Caballos 2001: 3-17. 


\section{LA TERRA SIGILLATA ITÁLICA:}

Fue a mediados del s. I a. C cuando surgió en la Península Itálica, y más concretamente en la ciudad de Arretium (Arezzo), la T.S. Itálica. Ésta fue configurándose como una nueva producción, inicialmente de formas lisas barnizadas en rojo, que venía a romper la antigua tradición de vajillas de barniz negro, que desde el s. V a. C. habían dominado las mesas de amplias zonas mediterráneas. La moda de carácter firme que se había consolidado en los servicios de mesa romanos durante la República se fundamentaba principalmente en la importación de cerámica "Campaniense", especie que pierde definitivamente su importancia y uso frente a los nuevos modelos de tonalidad rojiza, que comienzan a ser ampliamente demandados en torno al 30 a. C., cuando ya se incorpora la decoración y el uso del molde a las técnicas de producción de T.S.. Con ello, la manufactura de los servicios de mesa itálicos alcanza un alto grado de calidad y estandarización que ha llevado a que su fabricación sea considerada como una producción casi de carácter industrial (Pucci 1973: 255-257).

La aceptación y demanda de estos servicios de mesa promovieron durante la $2^{\mathrm{a}}$ mitad del s. I a. C. la creación en la Península Itálica de nuevos centros de elaboración. Este hecho se vio favorecido por la implantación de oficinas de producción dependientes de un taller matriz, que se consolidaron como sucursales que permitían un mayor acceso a los distintos cauces de distribución de cerámica, diversificando de esta manera la producción y permitiendo optar a mayores beneficios al ampliar el espectro de mercado. Esta expansión de los centros de producción itálicos se consolida con la formalización a fines del s. I a. C. (10 a. C. aproximadamente) del taller de La Muette (Lyon) en la Galia, entre cuyas oficinas se ha detectado la existencia de sucursales del taller matriz de Arretium (Wells 1977), así como moldes trasladados desde Arezzo a Lyon.

El nivel de producción de la T.S., su calidad y la situación favorable que se produce para el comercio marítimo y terrestre con el inicio de la Paz Augusta, fueron algunos de los factores que contribuyeron a la comercialización y distribución de estos productos itálicos en la Península Ibérica. Las escenas representadas en las primeras producciones decoradas en T.S. Itálica comienzan a ser distribuidas en un momento en el cual la política estatal romana se encuentra dominada por un fenómeno unificador bajo la figura de César Octaviano, en donde los elementos propagandísticos "de lo romano" encuentran un medio favorable en el que difundirse y afianzarse. La posibilidad de adquirir servicios de mesa de importación por parte de un mayor número de individuos, en un momento de fuerte romanización provincial como era el principado de Augusto, se vio favorecida por la incorporación de los gustos romanos en la mesa. La decoración cerámica se dispone como un mecanismo portante de elementos culturales de tradición latina que viste las comidas y reuniones, a la vez que ofrece una lectura basada en la mitología, las acciones cotidianas o la decoración arquitectónica que se estaba difundiendo desde la Península Itálica.

De estas primeras importaciones de T.S., los talleres itálicos representados en el conjunto que examinamos de Carmona son básicamente de procedencia aretina, con seis piezas seguras atribuidas a las oficinas de Felix (Fig. 1.4; Tab. 1.49), Vmbricius (Tab. 1.10), Rasinius sobre una forma Conspectus R-11 (Fig. 1.1; Tab. 1.5), M. Perennius (Tab. 1.6), A. Vibius Scrofula (Tab. 1.8) y Diomedes (Tab. 1.9), operario este último de A. Vibius Scrofula. De talleres aretinos o provinciales se han documentado cuatro piezas procedentes de las oficinas del conocido ceramista Ateius, de las cuales tres marcas pertenecen a sus trabajadores o libertos: dos firmadas por Crestus (Tab. 1.2 y Tab. 1.3), una perteneciente a Xanthus sobre una forma Conspectus 22.3, que por las características de la pieza podría proceder del centro galo de La Muette (Tab. 1.11) y una Conspectus 14 sellada

9. Las Tablas 1, 2 y 3 de marcas de alfarero referidas en el texto se encuentran publicadas en Vázquez 2002: 379-384, debido a ello se ha preferido no repetirlas en este trabajo remitiéndonos al anterior.

ISSN: 1133-4525 ISSN-e: 2255-3924

SPAL 13 (2004)

http://dx.doi.org/10.12795/spal.2004.i13.08 
por el propio Ateius (Tab. 1.1), ceramista bien documentado en la península Ibérica en lugares como Augusta Emerita (Pérez Outeriño 1990), Valeria (Sánchez-La Fuente 1985), Baelo (Bourgeois y Mayet 1991) o Conimbriga (Alarçao 1975). De Puteoli hemos documentado con seguridad una pieza firmada por Q. Pompeius Serenus sobre una posible Conspectus 33 (Tab. 1.7). En total, en la ciudad de Carmona, el estudio de las marcas de alfarero de procedencia itálica, ha permitido identificar con seguridad a once alfareros, con marcas que responden a seis tipos distintos ${ }^{10}$.

El resto del repertorio comprende formas como la Atlante XXVIII-Conspectus 7.4.1.2 ${ }^{11}$ (Fig. 1.8); Atlante XXII-Conspectus $15^{12}$ (Fig. 1.11); RITT. 5 A-Conspectus $22^{13}$ (Fig. 1.5); Conspectus $26^{14}$ (Fig. 1.10); RITT. 8-Conspectus 36.3.1 ${ }^{15}$ (Fig. 1.7); Conspectus 50.3.116 (Fig. 1.3); Atlante VIII-Conspectus $12^{17}$ (Fig. 1.13) o la Atlante X-Conspectus $18^{18}$ (Fig. 1.12), que conviven en contextos cerrados como el de Pozo Nuevo 5 (Belén, M. et al. 1998) y Calatrava 2 (Román y Vázquez. 2003), con cerámicas de imitación tipo Peñaflor, formas 9; 11; 12; 13 y 14 de Amores y Keay (1999), así como las formas IId y III de Martínez (1988). Otras formas documentadas son la Goudineau 7 (Fig. 1.9); Atlante XXIX-Conspectus $27.1^{19}$ (Fig. 1.6); la RITT. 5 B-Conspectus $23^{20}$ (Fig. 1.4), así como la Atlante XXXIX-Conspectus $28^{21}$ (Fig. 1.2), forma más reciente de las documentadas.

Estos productos itálicos llegarían a Carmo entre el 15 / 10 a. C., aproximadamente, y el segundo cuarto del s. I d. C., aunque tampoco hay que descartar que pudieron hacerlo en momentos anteriores, pero no contamos entre las piezas que hemos examinado con ningún sello en posición radial que pudiera adelantar estas fechas. La época tardo augustea, de acuerdo con las marcas que examinamos, supone el apogeo del comercio de T.S. Itálica en Carmo. La importación siguió

10. Rectangulares (uno de ellos intradecorativo), in planta pedis (tipo más frecuente a partir del $15 \mathrm{~d}$. C.: Ettlinger et al. 1990: 14 y 147), cuadrangulares (tipo conocido desde el inicio de la producción de T.S. y que continúa durante todo el periodo augusto), trilobulados (tipo característico de los talleres de Ateius durante el periodo tardoaugusto y tiberiano: Ettlinger et al. 1990: 147), ovalados y uno intradecorativo sin cartela realizado a mano alzada sobre el molde.

11. Este tipo se fabricó en los talleres de Arezzo, Pisa, Lyon así como en la región padana. Su producción comenzó con anterioridad al 30 a. C., continuándose durante toda la primera mitad del s. I a. C. hasta enlazar con la forma sudgálica Dragendorff 33, que viene a ser una evolución del modelo itálico. Su mayor apogeo se encuentra circunscrito al principado de Augusto.

12. Este tipo fue producido en los talleres de Etruria, Campania y Lyon, siendo una forma más propia de los talleres provinciales. Su producción comienza en torno al $10 / 8$ a. C.

13. La forma 22 es característica de la gran mayoría de los centros itálicos. Su cronología inicial de producción se estima entre el 10 y el 8 a. C. Estas copas muestran una amplia distribución documentándose en gran cantidad en casi todo el imperio romano junto a la forma 18 entre los principados de Augusto y Claudio.

14. A la copa carenada con borde recto, forma 26, es posible que pertenezca el ejemplar número 13 , con borde ligeramente oblicuo al exterior con acanaladura que diferencia el borde de la pared del cuerpo. El tipo 26 es probable que fuera producida en los talleres del centro y del norte de Italia, durante la primera mitad del s. I d. C.

15. El tipo 36 se produce en los talleres etrusco-campanos hasta el principado de Tiberio, enlazando con la copa de producción gálica Ritt. 8.

16. Tipo producido en talleres aretinos y provinciales.

17. Producida en los talleres etrusco-campanos desde el 15 a. C.

18. La forma $\mathrm{X}$, con borde vertical cóncavo-convexo, fue fabricada en todos los grandes centros de producción de T.S. Itálica, e introducida en la última década antes de Cristo, documentándose en pequeño número en Oberaden y Dangstetten.

19. Tipo producido en los talleres aretinos y provinciales. Su producción se inicia en torno al 10 a. C. difundiéndose sobre todo en el principado de Tiberio.

20. La forma 23 (Ritt 5 B) es producida en los talleres aretinos y provinciales. Aunque su morfología refleja una simplificación de la forma 22 (Ritt. 5 A), ello no implica una diferenciación cronológica clara. Su producción se inicia aproximadamente entre el 10 y el 8 a. C. Estas copas, muestran una amplia distribución entre los principados de Augusto y Tiberio.

21. Este tipo fue elaborado en los talleres de Puteoli principalmente. Su producción se inicia en un momento anterior al 15 d. C., para posteriormente enlazar con la forma gálica Dragendorff 4. 
durante la etapa tiberiana, como prueba la presencia de sellos in planta pedis característicos de este período ${ }^{22}$.

\section{LAS CERÁMICAS DE IMITACIÓN TIPO PEÑAFLOR}

La llegada de estas producciones itálicas al valle del Guadalquivir provocó la formalización en época de Augusto de un centro de producción de "Sigillatas de Imitación Tipo Peñaflor ${ }^{23}$ " en la Baetica, antes de iniciarse la producción de T.S. Hispánica en los talleres de la Tarraconense o de la propia provincia Bética y momentos antes de comenzar la comercialización de la T.S. Sudgálica en el suroeste peninsular. Respecto a este grupo cerámico de producción en serie, y con un marcado carácter provincial en cuanto a sus principales áreas de distribución, no existe de manera consensuada un criterio terminológico unitario, ya que su estudio se encuentra aún en los inicios de su definición como "especie cerámica" o "grupo independiente" de la designada T.S. ${ }^{24}$.

La previa existencia de clasificaciones tipológicas concernientes a las especies cerámicas imitadas permite su aplicación a los productos del alfar de Peñaflor mostrando de esa manera una equivalencia tipológica con sus modelos que simplifica su clasificación y perpetúa científicamente el criterio de imitación que caracteriza a estas producciones. Por ello se ha impuesto principalmente para su clasificación el uso del Conspectus Formarum para las imitaciones de T.S. Itálica o la tipología de Dragendorff para las imitaciones de sudgálicas, fomentando la aplicación de equivalencias entre originales y copias, no quedando aún del todo establecida una tabla tipológica propia. Recientemente ha sido publicada la tabla tipológica preliminar para las "formas precoces" de imitación de Peñaflor en las que se distinguen hasta 14 tipos distintos (Amores y Keay 1999: 249-250). Toda la producción sintetizada en Peñaflor refleja una clara adscripción más o menos próxima a modelos de importación comercializados en la zona. En el caso de la imitación de tipos sudgálicos, hispánicos o africanos, aún no ha sido presentada una tabla tipológica al respecto, aunque es aconsejable el uso de las existentes para los modelos imitados ${ }^{25}$.

Del Primer Momento Imitacional, equiparable a las "producciones hispánicas precoces" (Serrano 1999: 231), se han documentado las formas 9 (Fig. 2.4); 11 (Fig. 2.7); 12 (Fig. 2.5); variante de la Forma 12 (Fig. 3.2); 13 (Fig. 2.2) y 14 (Fig. 2.1 y 2.6) de Keay y Amores. El Servicio "b" de Peñaflor (correspondiente a la Forma 14) compuesto por los Tipos Ib (copa) y IIb (plato), es el que

22. Uno de los factores que favorecieron la activación del comercio de vajillas de lujo durante el periodo tardoaugusteo y tiberiano, debió de ser la prosperidad que vivió la ciudad de Carmo bajo los dos primeros emperadores; prosperidad que no pasaría desapercibida a los comerciantes que debieron encontrar en Carmona un mercado más receptivo y con mayor demanda de productos.

23. Recientemente hemos tratado, a partir de los materiales de la necrópolis astigitana, el estado de la cuestión concerniente a las producciones celticenses, por lo que a él nos remitimos (Vázquez, García Fernández, y González Parrilla 2004, en este mismo volumen)

24. El actual conocimiento que poseemos sobre este grupo cerámico no ha permitido aún sentar unas bases firmes que permitan explicar una traza de producción como la detectada en Celti. El proceso de formalización y desarrollo que se desprende del análisis de los productos celticenses comporta unos datos que distinguen, por presentar unas características propias, la configuración de este centro productor de "sigillatas de imitación tipo Peñaflor" (Amores y Keay 1999: 235) de los procesos de formalización de talleres de T.S. Hispánica en la Bética o la Tarraconense.

25. El conocimiento de los materiales exhumados durante la V Fase de Excavaciones Arqueológicas de Urgencia en el solar del antiguo mercado de la Encarnación nos ha permitido documentar en Hispalis la comercialización de la copa (Drag.-Forma) 24 / 25 en T.S. de Imitación Tipo Peñaflor (agradecemos la información al Dr. Fernando Amores). De igual manera, la comercialización de imitaciones de modelos sudgálicos / hispánicos ha sido documentada en Astigi (Vázquez.; García Fernández, y González Parrilla 2004, en este mismo volumen).

ISSN: 1133-4525 ISSN-e: 2255-3924

SPAL 13 (2004)

http://dx.doi.org/10.12795/spal.2004.113.08 
presenta un mayor índice de producción y un mayor radio de comercialización en Carmona. El inicio de su producción coincide con el momento de mayor dispersión por la Bética de los productos de Celti en un momento, fines del principado de Augusto y el principado de Tiberio, en que ya se ha consolidado la red de distribución que a nivel terrestre se materializó con la finalización de la vía Augusta en el año 2 a. C. Alcanza su mayor índice de producción en tiempos de Claudio / Nerón, perdurando durante buena parte del s. I d. C., circunstancia que se ha documentado en San Felipe 1A, junto a imitaciones de Barniz Rojo-Pompeyano correspondientes a la forma III de Martínez (Fig. 3.4 y 3.5), e importaciones sudgálicas e hispánicas en contextos avanzados de mediados del s. I d. C. El tipo IId de Martínez (Fig. 3.3) se encuentra escasamente documentado. Similar a la forma itálica Consp. 3.1, y a la forma gálica Drag. 18 (Fig. 3.1), se ha documentado un ejemplar en San Felipe 1A, en niveles de la $2^{\mathrm{a}}$ mitad del s. I d. C., mientras que no se ha asignado equivalencia tipológica a una pieza de contextos de mediados- $2^{\mathrm{a}}$ mitad del s. I d. C., que por sus características procede del taller de Celti (Fig. 3.3).

\section{LA TERRA SIGILLATA SUDGÁLICA}

Durante el período tardo augusteo y el principado de Tiberio se formaliza en el este de la Galia el inicio de la producción de T.S. Sudgálica partiendo de la base de los conocimientos técnicos itálicos. La instalación de talleres se origina en un momento en el cual las redes de distribución se encuentran consolidadas y soportan un importante trasiego de mercancías de un punto a otro ${ }^{26}$. La creación de estos talleres responde por ello a un sistema de implantación de centros alfareros en puntos nodales concretos, con el objetivo principal de obtener una comercialización del producto en un radio de alto y bajo alcance, accediendo principalmente a enclaves de "consumo y comercio" como eran las ciudades o campamentos.

Al producirse la implantación de estos centros alfareros de producción de T.S., en este caso Sudgálica, la tecnología hubo de importarse desde centros preexistentes por medio de artesanos especializados en su fabricación. Ello provocó la igualdad de técnicas y tratamiento, así como la manufactura de modelos existentes y conocidos de antemano por fabricantes, distribuidores y vendedores, consiguiéndose con ello asegurar el éxito del producto. De manera más o menos conjunta se fueron creando oficinas y pequeños centros alfareros que paliaban la demanda a nivel regional o local y que crearon una amplia red de talleres en el este de la Galia ${ }^{27}$. La instauración de estos centros de producción provocó la creación de nuevas series tipológicas, tanto en formas lisas como decoradas (Vernhet 1986), que junto con otras características propias de estos alfares permiten su individualización y caracterización como subespecie aparte de la Itálica, al igual que sucede con la producción Hispánica.

De los treinta y ocho sellos de alfarero documentados (todos pertenecientes a formas lisas y ubicados en el fondo interno de las piezas) ${ }^{28}$, solamente se han podido identificar con claridad veinte que indican que las oficinas ubicadas en el centro de La Graufesenque (actual Millau) son

26. La comercialización de T.S. Itálica y T.S. Sudgálica encontró una situación favorable para su distribución en el movimiento y acantonamiento de tropas en el limes, como muestra el estudio de la procedencia de las piezas de $C$. Ateius en el campamento de Haltern (Wells 1977: 3-4)

27. Sobre la formalización de los talleres del Grupo del este (de La Graufesenque), véase Bemont y Bourgeois 1986.

28. Bien es cierto que alguna de las marcas conservadas y no adscrita a forma alguna pudiera corresponder a vasos decorados, pero nos es imposible saberlo ya que no podemos adscribirlo a forma alguna a partir de un resto fragmentario o de un fondo indeterminado. 
prácticamente las únicas que comercializan sus productos en el mercado carmonense. Tenemos que tener en cuenta que hay determinados ceramistas cuyas oficinas también se documentan en centros como Montans ${ }^{29}$, aunque el análisis visual de las piezas nos inclinan a considerarlos procedentes del denominado "grupo de La Graufesenque" ${ }^{30}$. Todas los alfareros documentados lo están con una sola marca a excepción de la officina de época Flavia de Angius $^{31}$ de la cual contamos con dos ejemplares, una en un fondo de forma indeterminada (Tab. 2.26) y otra sobre un plato Drag. 15/17 (Tab. 2.25).

La forma sobre la que mayor número de marcas se ha documentado en Carmona es, con 12 ejemplares, la copa Drag. 27 (Fig. 4.3) seguida con 9 ejemplares del plato Drag. 18-18/31 (Fig. 4.5); sobre la forma Drag. 24/25 (Fig. 4.2) solo hay identificadas tres marcas ${ }^{32}$; del plato Drag. 15/17 (Fig. 4.6) hemos documentado un ejemplar; y de la copa Ritt. 8 (Fig. 4.1) otro ejemplar, mientras que no hemos identificado ningún sello que pertenezca a una forma decorada. Los productos fabricados con la característica técnica de la marmorata, propios del centro de La Graufesenque y que se fechan entre el 40 d. C. y el 70 d. C. aproximadamente, no son desconocidos en la ciudad de Carmona, aunque en este trabajo sólo presentamos una pieza (Tab. 2.34) con marca de alfarero no identificada debido a la mala impresión del sello sobre el fondo interno de una copa Drag. 24/25.

Aunque se ha documentado piezas firmadas por alfareros cuya producción comienza en época de Tiberio, caso de Potitus (Tab. 2.47) y Amandus (Tab. 2.24) llegando la actividad del primero a Nerón y la del segundo a Vespasiano, la cronología de la mayoría de las piezas está comprendida entre los reinados de Claudio / Nerón y de Nerón / Vespasiano. De estos dos momentos, hemos documentado los productos provenientes de las oficinas de Successus (Tab. 2.50), Modestus (Tab. 2.41), Passienus ${ }^{33}$ (Tab. 2.45), Masclus (Tab. 2.40), Sentrus (Tab. 2.49), Macer (Tab. 2.39), la asociación de los alfareros Valerius y Valerius (Tab. 2.52) del periodo Claudio / Nerón, así como la Forma decorada Drag. 30 (Fig. 5.2). Las marcas cuya cronología llega hasta Domiciano pertenecen a los alfareros Vitalis (Tab. 2.53), Sabinus ${ }^{34}$ (Tab. 2.48) y Patricius ${ }^{35}$ (Tab. 2.46), si bien es cierto que las formas Drag. 35 (Fig. 4.4), 36 (Fig. 5.1) y 37 (Fig. 5.3) están ampliamente representadas en registros arqueológicos que alcanzan el s. II d. C.

Por lo tanto, durante el segundo cuarto del s. I d. C (entre fines del período tiberiano y el reinado de Calígula) podrían ser ya adquiridos en Carmona los primeros productos importados desde el centro alfarero de La Graufesenque y que formarían parte de las vajillas domésticas carmonenses

29. Amandus (Tab. 2.24), Potitus (Tab. 2.47) o Sabinus (Tab. 2.48) (Oswald 1920 red.1983: 14, 272 y 244).

30. Dentro de este grupo se encontrarían, entre otros, los centros de La Graufesenque y el de Banassac (Bemont y Jacob 1986).

31. A través del análisis de una serie de grafitos conservados en La Graufesenque que se relacionan con el alfarero Angios / Angius, se propone que éste podría haber iniciado su producción no en época Flavia sino a fines del periodo Claudio (Bemont 1976).

32. Sobre Drag. 27 se documentan los alfareros Cinus (Tab. 2.29), T. Iulius Apias (Tab. 2.31), Iustus (Tab. 2.32), Macer (Tab. 2.39), Passienus (Tab. 2.45) y Valerius y Valerius (Tab. 2.52); en Drag. 18-18/31 a Lentulus (Tab. 2.37), Modestus (Tab. 2.41), Patricius (Tab. 2.46) y Sabinus (Tab. 2.48); en Drag. 15/17 a (vof)Angius (Tab. 2.25); sobre Ritt. 8 a Cennatus (Tab. 2.28) y en Drag. 24/25 al alfarero Successus (Tab. 2.50) y Firmo (Tab. 2.30).

33. Esta marca se encuentra impresa en posición retrógrada, hecho ya documentado en Valentia (Ribera Lacomba 1981: Fig. 6 núm. 19).

34. La marca de la officina de Sabinus se encuentra sobre una Drag. 18, tipo que deja de fabricarse antes del reinado de Domiciano.

35. Aunque sabemos que el número de ejemplares con el que hemos trabajado es pequeño, nos ha permitido acercarnos a esta subespecie cerámica y empezar a acotarla cronológicamente. Aun así, es indispensable la pronta realización de un estudio sobre la decoración de las piezas sudgálicas con el fin de contrastar los datos extraidos de las marcas con los que se desprendan del estudio de las decoraciones y las formas sobre las que éstas se presentan.

ISSN: 1133-4525 ISSN-e: 2255-3924

SPAL 13 (2004)

http://dx.doi.org/10.12795/spal.2004.113.08 
junto con las ultimas importaciones itálicas que no superarían los inicios del reinado de Claudio ${ }^{36}$. En este momento las importaciones sudgálicas se hacen más frecuentes y regulares, consolidándose su comercio durante el reinado de Nerón y los inicios de Vespasiano, para decaer fuertemente bajo Domiciano-Trajano, cuando los productos hispánicos, que ya se encuentran presentes en Carmona desde mediados del s. I d. C. ${ }^{37}$, serían mayoritarios frente a los gálicos. Este descenso y práctica finalización de las importaciones gálicas desde el reinado del emperador Domiciano han sido constatados en muchos otros yacimientos peninsulares. ${ }^{38}$

\section{LA TERRA SIGILLATA HISPÁNICA}

En torno al 40 / 50 d. C. se inicia la producción de T.S. Hispánica en el Norte y Sur de la Península Ibérica de manera prácticamente sincrónica ${ }^{39}$. La formalización de los principales talleres peninsulares responde más a la activación de centros alfareros desde planteamientos "empresariales" y preestablecidos, que a un proceso imitacional basado en técnicas locales preexistentes, como es el caso del ya comentado centro imitacional de Celti. En la instalación de las primeras oficinas de T.S. Hispánica primaría, pues, el conocimiento de unas técnicas concretas, un repertorio tipológico existente vinculado a esas técnicas y la existencia de una situación favorable del mercado de cerámica fina de mesa en las provincias occidentales del imperio ${ }^{40}$.

Se ha supuesto que la configuración del fenómeno de instalación de talleres de T.S. Hispánica en áreas concretas del norte peninsular, como el valle del Najerilla, responde a la implantación de una producción en una región concreta con la intención inicial de superar los marcos del mercado local o regional ${ }^{41}$. En el caso del principal centro productor de la Bética ubicado en Los Villares de

36. Siempre hemos de tener en cuenta el fenómeno de perdurabilidad de determinadas piezas, que por su valor económico, estético, funcional, familiar o personal prolongan su uso en el tiempo después de que éstas ya no se fabriquen o importen.

37. En las excavaciones realizadas en la Puerta de Córdoba (Carmona) se documentó una base de T.S. Hispánica fechada en época tiberiana y que apunta a "un estadio muy inicial, de ensayos" (Ojeda 2001: 183).

38. Es el caso de Elda (Poveda y Ribera Lacomba 1985: 158), Valencia (Ribera Lacomba 1981: 310), Cartagena (Castellano 2000: 158 y 164) o Ilici en donde "el reinado de Domiciano supone un mantenimiento medio, y el final de los Flavios el hundimiento de la importación" (Montesinos 1998: 193).

39. Sobre la formalización y producción de los talleres hispanos véase: Mezquíriz 1961, Roca 1976 y Garabito 1978. Actualmente los datos indican que es a mediados del s. I d. C. cuando se inicia la producción de T.S. Hispánica en los talleres del norte (Mezquíriz 1985: 97-174). En el caso de los talleres de Andújar, el inicio de la producción se sitúa entre el principado de Tiberio y Claudio, centrándose la primera fase con Claudio (Fernández 1987: 482-489).

40. El conocimiento de las composiciones decorativas que se estaban empleando en los talleres de la Galia y, la conformación exacta de las series gálicas que se ponen en producción en la Península Ibérica, evidencian la influencia que desde el conocimiento del funcionamiento de los talleres gálicos se dio en el inicio de las producciones hispánicas en el norte peninsular. La escasez de excavaciones arqueológicas en los centros alfareros del norte peninsular, impiden realizar una valoración acerca de la instalación de sucursales que pudo darse dentro del propio fenómeno de formación de talleres norteños con el fin de diversificar la producción. A este respecto hay que mencionar los estudios que apuntan hacia una vinculación entre el complejo de Tritium Magallum y los talleres de Calagurris (Sáenz y Sáenz 1999: 61-136) con base en estudios estilísticos y analíticas de espectrometría de emisión atómica con I.C.P., o con los de Andújar en la Bética sobre la base del hallazgo de marcas de alfarero idénticas, estando esta cuestión en sus inicios. En el sur peninsular los estudios apuntan hacia una relación directa entre la instalación de los talleres malagueños y granadinos con el centro alfarero de Los Villares de Andújar (Roca 1976 y Serrano 1991).

41. De ahí que la T.S. Hispánica se introduzca en las rutas comerciales entre provincias. Su comercio ha sido detectado como una constante durante la segunda mitad del s. I y los inicios del s. II en el norte de África (Boubé 1965) y sur de la Galia (Mezquíriz 1961: 210-214.). En las provincias romanas de la Península Ibérica, el comercio y distribución de la T.S. 
Andújar su implantación ${ }^{42}$ debió de ser similar con el fin de satisfacer principalmente el mercado del sur peninsular y del norte de África.

La distribución desde ambos focos productivos se fundamentó sobre la base de las principales vías de comunicación a su alcance, distribuyéndose por medio de una comercialización tanto terrestre como fluvial, en que jugaron un gran papel los grandes ríos como el Ebro ${ }^{43}$ o el Guadalquivir ${ }^{44}$, y terrestre; en el caso del complejo alfarero de Tritium Magallum se ha detectado un uso masivo de las vías terrestres hacia el noroeste peninsular y la Lusitania, en la que la ciudad de Augusta Emerita sería el principal centro redistribuidor ${ }^{45}$. En la distribución de los productos de Andújar el uso de la vía Augusta o los ramales que partían de ella permitieron una comercialización masiva de sus productos en el interior de la Bética y en la $\operatorname{costa}^{46}$. La comercialización marítima se vio fomentada por el contacto permanente entre los grandes centros portuarios de la costa peninsular, que contaban con un alto nivel de trafico de mercancías que enlazaba en ambas direcciones desde el sur de la Galia, y toda la costa hasta las ciudades de Baelo Claudia ${ }^{47}$ y Malaca, tradicionalmente vinculadas al comercio con el norte de África.

Sobre las marcas de alfarero en T.S. Hispánica procedentes de Carmona y conservadas en el Centro de Interpretación de la Ciudad poco podemos decir dado el escaso número de piezas publicadas (diez en total) y el mal estado de conservación que éstas, tienen impidiendo una perfecta asignación a un centro productor determinado o a un alfarero concreto. Las formas que hemos identificado con marca son, con dos ejemplares, la copa Drag. 27 (Fig. 6.5), con un ejemplar el plato 18 (Fig. 6.6) y el plato Drag. 15/17 (Fig. 6.4). El análisis de las piezas nos indica la confluencia en Carmona de productos procedentes de dos áreas bien diferenciadas como es la jiennense (Los Villares de Andújar) ${ }^{48}$ y la riojana; Al ceramista Lapillius (Tab. 3.66), del taller de Tritium Magallum ${ }^{49}$, se ha asignado la pieza número 66, tanto por sus características físicas como por el análisis de la marca ${ }^{50}$. Las formas sobre las que no se ha documentado marcas de alfarero son la 8 (Fig. 6.1), 33 (Fig. 6.2), 35 (Fig. 6.3); 29 (Fig. 7.1) y 37 (Fig. 7.2 y 7.3).

Hispánica es donde alcanza su mayor desarrollo en esas fechas (Escrivá 1989; Mayet 1984 y Roca 1991: 221-235); con menor intensidad se comercializaron en otras provincias romanas.

42. El centro alfarero de Los Villares de Andújar muestra en sus orígenes algunas influencias de las formas itálicas (Roca 1978: 285-302.), estando su repertorio inicial vinculado más al ambiente tipológico gálico y a la manufactura de formas exclusivamente hispánicas o propias del alfar (formas Andújar. 1-9).

43. Que enlazaba la zona riojana con la importante ciudad de Caesaraugusta y la costa noreste peninsular.

44. El uso del Guadalquivir para el transporte de mercancías se encuentra ampliamente documentado a través de las fuentes clásicas, la epigrafía y los hallazgos de alfares anfóricos a lo largo de su curso que muestran un uso intensivo del río para el transporte.

45. En un principio, Augusta Emerita fue identificada como sede de los talleres de Valerius Paternus y Lapillius (Mayet 1970: 5); posteriormente, la revisión efectuada sobre la ubicación de las oficinas de estos alfareros, que se encuentran ampliamente documentados en la zona de Tricio, avalan la hipótesis que ve a Augusta Emerita como un gran centro redistribuidor de T.S. Hispánica.

46. Se ha propuesto que el uso de las vías que enlazaban el centro alfarero de Andújar con la costa malagueña facilitaba la comercialización de los productos fuera de la Península Ibérica a través del puerto de Malaca, que funcionaría como uno de los principales puertos redistribuidores hacia el norte de África. Sobre la comercialización de los productos de Andújar véase: (Sotomayor 1972: 263-289; Serrano 1983: 151-157).

47. Los trabajos realizados en el yacimiento de Baelo muestran que la mitad de la T.S. Hispánica documentada procede de los talleres de la Rioja y la otra mitad de los talleres béticos (Bourgeois y Mayet 1991), indicando la importancia de las ciudades costeras del sur como centros receptores y distribuidores de las producciones hispánicas hacia otros puertos o hacia el interior de la Península Ibérica; en el caso de Valentia, las importaciones son principalmente desde talleres del norte de Hispania (Escrivá 1991).

48. Véase Sotomayor (1998) y Sotomayor et al. (1999).

49. Sobre este taller véase Garabito 1978.

50. De este sello solamente se conserva ...OLA..., con la letra L en grafía arcaica; el uso de letras arcaicas es frecuente en las producciones hispánicas (Mezquíriz 1961: 45) y, dentro de éstas, está ampliamente documentado en las del alfarero tritiense Lapillius (Garabito y Solovera 1976: 16).

ISSN: 1133-4525 ISSN-e: 2255-3924

SPAL 13 (2004)

http://dx.doi.org/10.12795/spal.2004.113.08 
El taller de Andújar está representado por cuatro ejemplares de los que resaltamos una marca sobre fondo indeterminado en la que se lee C V (Tab. 3.65). Su atribución al taller de Los Villares de Andújar ha sido realizada no sin ciertas dudas, ya que en los talleres riojanos también se encuentran documentados sellos de alfarero con grafía C V, por lo que han sido las características de la pasta y el barniz las que nos han inclinado finalmente a atribuirlo al taller jiennense. Los talleres riojanos están documentados en Carmona con tres marcas, siendo el taller de Tritium Magallum el mejor representado con alfareros como Lapillius (Tab. 3.66); a su vez el taller riojano de Bezares podría estar representado por la marca C I (A) ${ }^{51}$ (Tab. 3.64) como uno de los centros abastecedores de T.S. Hispánica en Carmona.

Somos conscientes de que sólo podemos aproximarnos a la realidad de lo que fue el comercio de T.S. Hispánica. en la ciudad romana de Carmo a través de un análisis profundo de una amplia muestra de especímenes hispánicos, ya que el simple análisis de diez marcas de alfarero que en su mayoría se encuentran fragmentadas (imposibilitando con ello su identificación), si bien nos permite comenzar a apuntar hechos, como es la constatación del comercio de piezas riojanas y jiennenses en Carmo, el inicio de las importaciones a mediados del s. I d. C. y la continuidad de las importaciones durante la $1^{\text {a }}$ mitad del s. II d. C., con las que podemos elaborar hipótesis de trabajo, aunque no obtener una visión clara de su comercio e importancia que sí se refleja en los materiales no sellados.

\section{CONCLUSIONES}

La distribución de productos destinados a un consumo de semi-lujo como la T.S. u otras importaciones de carácter similar, ya sean cerámicas de paredes finas, lucernas o ungüentarios, no ha sido a nuestro juicio explicada de manera satisfactoria. La T.S. y los productos cerámicos de similares características han sido considerados por la investigación como una manufactura de exportación secundaria o, como se la ha designado especialmente, de "relleno" 52 . El análisis de su distribución se ha cimentado sobre una comercialización efectuada dentro de un circuito comercial con un radio de alto / medio alcance ${ }^{53}$, que incluía en las bodegas de los navíos comerciales estos menajes como complemento a la carga principa ${ }^{54}$. Esta circunstancia impide defender la efectividad de una compleja red de comercialización directa entre centros productores como Arezzo, La Graufesenque o La Rioja y enclaves muy determinados como la ciudad de Carmo en el Bajo Guadalquivir. Este hecho nos obliga a reflexionar sobre el comercio indirecto entre las zonas de producción y la inmensa mayoría de los asentamientos en los que se evidencia la presencia de esta especie cerámica.

51. Las marcas in tabula ansata son conocidas sobre Drag. 15/17 y Drag. 27 en las producciones hispánicas aunque son poco frecuentes (Fernández 1998: 80); la hemos relacionado con la marca C I A E F de Bezares con una cronología anterior al s. II d. C.

52. El auge expansionista de los productos de La Graufesenque, por ejemplo, ha sido explicado a través del incesante tráfico naval que tenía el puerto de Narbona, en donde estas cerámicas eran "embarcadas como mercancía de relleno en las naves africanas, béticas o itálicas que hacían el viaje de regreso" (Beltrán 1990: 29).

53. No incluimos en esta afirmación el comercio regional de T.S. que se daba entre los alfares y los núcleos de población cercanos, que, por citar ejemplos de la Bética, ha sido documentado en los talleres antequeranos por Encarnación Serrano (1997: 219 y 224).

54. El análisis del pecio Port-Vendres II fechado entre el 41/42 d. C., que había partido de la Bética con un cargamento compuesto principalmente por ánforas (olearias, vinícolas y de conservas) y lingotes de plomo y cobre, transportaba a su vez cerámicas de paredes finas que "constituaient certainement un petit complément de cargaison" (Colls et al 1977: 7). 
El comercio directo sería frecuente desde los lugares de producción hasta las localidades cercanas y, para una distribución masiva, hasta las ciudades litorales más próximas a los alfares, con disposición de infraestructuras portuarias que proporcionasen los medios suficientes para una fácil introducción de la producción cerámica en el circuito comercial marítimo ${ }^{55}$. A través de las rutas comerciales marítimas que atravesaban el Mediterráneo y enlazaban con el Atlántico se alcanzaban puertos retirados de la comarca originaria de producción ${ }^{56}$, en los cuales se generaba con el arribo de mercancías una demanda de mercadería importada, o se satisfacía una ya existente.

Este trayecto entre puertos, que puede ser estimado como "directo" ya que el destino límite de la nave convenía que fuera conocido por todo aquél que poseyera intereses en él, estaría encauzado en gran medida por negotiatores y mercatores a los que les afectaría la saturación de un mercado, con una gran representación de productos iguales de semi-lujo, por lo que es muy factible que la distribución de la carga se efectuase entre distintos establecimientos portuarios. Un cargamento de "relleno" de T.S., probablemente no tendría un punto fijo de desembarque, sino varios, que estarían estrechamente interrelacionados con las diferentes escalas que efectuara el navío mercante antes de atracar en su lugar de destino.

En el caso de la Bética, se localizan significativos puertos navales como el de Gades, o el de Hispali $^{57}$ que fueron empleados como destino final de gran número de naves comerciales, o como importantes escalas en trayectos más largos. En las instalaciones portuarias de Gades $^{58}$ o Hispalis ${ }^{59}$ se embarcaban, descargaban y almacenaban gran cantidad de productos de todo tipo dando lugar a nuevos procesos de redistribución, al ser estos dos enclaves portuarios puntos principales de salida, entrada y colocación de productos en el Bajo Guadalquivir.

Sabemos que la provincia senatorial de la Bética, desde época de Augusto se encontraba articulada por dos ejes principales, que manifiestan la existencia de dos sistemas desiguales de transporte: el eje marítimo / fluvial ${ }^{60}$ y el eje terrestre ${ }^{61}$, y que ambos itinerarios articulaban las cuatro cabezas administrativas de la provincia desde la división de la Bética en cuatro conventus jurídicos por Augusto (Chic 1997: 35).

55. El centro alfarero de Puteoli utilizó su propio puerto para distribuir sus productos por el Mediterráneo, mientras que el grupo de La Graufesenque utilizó el de Marsella. En el caso de la Bética, los talleres de Los Villares de Andújar emplearon los puertos del sur peninsular para hacer llegar sus productos al Norte de África, o los puertos de la desembocadura del Ebro en el caso riojano.

56. Está ampliamente demostrado que era totalmente inviable la distribución masiva de productos cerámicos a miles de kilómetros de distancia a través de las vías terrestres existentes, por lo que el uso del medio acuático, ya sea marítimo o fluvial, venía a abaratar los costes del transporte, de manera considerable, a la vez que ofrecía una mayor seguridad a la carga cerámica durante el trayecto (Chic 1997: 61-62).

57. Durante el período republicano, el puerto de Hispalis aparece nombrado por Julio César, que nos informa sobre la existencia de unos astilleros que rivalizaban con los de Gades (César Bell. Civ., 2, 18, 1), a la vez que es en este puerto donde Casio Longino a mediados del s. I a. C., reúne a la flota cesariana (Hircio Bell. Alex).

58. Sabemos que el puerto de Gades, fue un punto principal de captación y distribución de cereales, y productos derivados de la mar, salsas, salazones, etc, que eran importados y consumidos por todo el imperio.

59. El puerto de Hispalis, durante el alto imperio, jugó un importante papel en la distribución de productos annonarios, que, siguiendo las rutas atlántico / mediterráneas, cubrían las necesidades de los ejércitos fronterizos y del pueblo de Roma. La masiva presencia de ánforas de la Bética procedentes del control hispalense y astigitano en lugares como Britannia, Germania o la propia Roma, muestran el trasiego de naves mercantes que tuvo el puerto de Hispalis al servicio de la administración y el funcionamiento del Estado Romano (Chic 1985 y 1987; Remesal 1986). Sobre el puerto de Hispalis véase Tabales (2001): 410-416; Tabales y Jiménez (2001): 383-385 y Ordóñez (1998).

60. Nos referimos a los tramos Gades-Hispalis (marítimo), e Hispalis-Corduba (fluvial); véase sobre el tema Corzo y Toscano (1992).

61. Sobre todo a partir del principado de Augusto, momento en el cual (2 a. C.) se termina el sistema de comunicaciones de la Vía Augusta Corzo y Toscano (1992).

ISSN: 1133-4525 ISSN-e: 2255-3924

SPAL 13 (2004)

http://dx.doi.org/10.12795/spal.2004.113.08 
Por estos dos ejes se moduló predominantemente la comercialización de productos como se ha venido corroborando en la Bética a través de distintos estudios arqueológicos e históricos ${ }^{62}$. No obstante siempre se ha dado mayor primacía a la ruta marítimo / fluvial sobre la ruta terrestre. Esta mayor atención e importancia de las vías hídricas no es exclusiva de la investigación en el contexto económico del Bajo Guadalquivir, sino que ha sido aplicada a todo el Imperio Romano de manera genérica, por lo que se ha llegado a afirmar que el transporte por tierra de productos voluminosos como cereales, alfarería, metales o maderas no podía ser realizado por individuos no vinculados al Estado o a comunidades ricas y poderosas por el alto coste que requería (Finley 1975: 177-181). Ciertamente, esta afirmación solamente asume y afecta al comercio "voluminoso" a larga / media distancia, y no a la comercialización de cerámicas, telas y objetos de semilujo en pequeñas cantidades y en trayectos de corto recorrido, que sí alcanzaba a ser efectuada por sujetos en solitario, adquiriendo una rentabilidad con ello ${ }^{63}$.

Carmo, ciudad ubicada en el Bajo Guadalquivir a $35 \mathrm{Km}$. de la ciudad portuaria de Hispalis, se abastecía principalmente de los productos de importación que penetraban en barco a través del Guadalquivir. Desde nuestro punto de vista, tendrían un gran peso las mercancías que, transportadas por el Lacus Ligustinus, remontaban el estuario del río hasta el puerto hispalense, lugar desde el que los productos descargados se redistribuirían hacia otras localidades de la Bética.

Como indicábamos, la comercialización de productos importados recurrió por el Bajo Guadalquivir a procedimientos desiguales para colocar sus mercancías en localidades como Carmo, con la salvedad de que Carmo no contaba en principio, con un enclave portuario inmediato ${ }^{64}$, por lo que es incuestionable que en último caso se emplearon los accesos terrestres para ello ${ }^{65}$. Sin embargo, ciudades cercanas sí poseían, debido a su ubicación inmediata al río Guadalquivir, de infraestructuras de embarque y desembarque de mercancías ${ }^{66}$. Hasta Hispalis, sabemos por noticias de Estrabón (III,2,3) que subían los grandes barcos mercantes, mientras que a Ilipa Magna (Alcalá

62. Para el transporte fluvial por el Guadalquivir, véase Chic 1990. Sobre las vías terrestres en la Bética véase Silliéres (1990) y Corzo y Toscano (1992).

63. Hemos de tener en cuenta que el precio de los productos comercializados por vía terrestre sufrían un incremento en su coste final relacionado con la distancia recorrida.

64. En Roma en el monte Testaccio, se ha documentado la marca PORT CARMO (con nexo R-T y C-A-R-M), que hace referencia a la existencia de un posible portus fluvial en las proximidades de la ciudad de Carmo (C.I.L. XV, 3126 en Chic 1985: 96 y 97). La ubicación de un portus en sus cercanías, viene apoyada además por la existencia de una serie de marcas de alfarero sobre ánforas oleícolas halladas en tres complejos alfareros junto al Corbones y muy próximos entre si, que encierran la forma abreviada P.C, que G. Chic ha desarrollado con reservas como Portus Carmonensis. Este enclave se correspondería muy posiblemente con una esclusa cuya función sería regular el nivel de las aguas del río y facilitar la navegación por el Corbones hasta el yacimiento del "Villar Tesoro" (Chic 1985: 96 y 97). Si bien el Portus Carmonensis no era realmente un puerto fluvial, sí debió de tener un punto de carga y descarga que facilitase la comercialización de los productos procedentes de los tres alfares mencionados con anterioridad y, por consiguiente, la llegada a este desembarcadero de mercancías que subían o bajaban por el Guadalquivir y se introducían por el Corbones.

65. En el año 1997, en el transcurso de una Intervención Arqueológica de Urgencia, se documentó una gran estructura de sillares, que ha sido acertadamente identificada por su excavador como un edificio con carácter público destinado al almacenamiento de grano (Román 2001). Estas instalaciones se sitúan en las cercanías de una de las puertas de la ciudad conocida actualmente por el nombre de Puerta de la Sedía. De dicha puerta partía uno de los caminos que daban acceso directo al Guadalquivir, que facilitaría con ello el transporte y las tareas de carga y descarga del cereal (Román 2001: 249).

66. Conocemos cuatro epígrafes dedicados a Antonino Pío y a Marco Aurelio procedentes de Hispalis, en los que los dedicantes son los barqueros fluviales (scapharii) que con sus scaphae se encargaban de transportar productos para la annona (C.I.L.A. II. I 8, 9, 26). En la Puerta de Carmona de la capital hispalense se encontraba una inscripción que nos habla de los lyntrarii Cananienses, Oducienses y Naevenses (C.I.L.A. II.I. 30). Las lyntrae eran barcas que trabajaban subiendo y bajando productos por el Guadalquivir al menos entre Hispalis / Ilipa Magna y el Corbones, utilizando embarcaderos ubicados en el curso del río para la carga y descarga de mercancías, por lo que jugaban junto con las scaphae un importante papel en el comercio por el Bajo Guadalquivir. 
del Río) llegaban sólo los pequeños, por lo que en uno de estos dos lugares convenía la descarga de los productos para su ulterior colocación río arriba con barcazas, o bien con carros y burros hasta espacios de hábitat próximos ${ }^{67}$.

Por medio de estos barqueros que con sus pequeños esquifes (scaphae o lyntrae) navegaban a lo largo del Guadalquivir, parte de la T.S. junto a otros productos de importación que arribaban a Hispalis / Ilipa Magna se ubicaría en los diferentes puntos de descarga instalados entre esta última y el Corbones. Desde estos enclaves se consumaba el circuito comercial emprendido en los alfares productores y se iniciaba un fenómeno de comercialización de corto recorrido, que vinculaba entre sí a localidades emplazadas entre el Corbones e Hispalis, por medio del comercio local entre asentamientos. El mercado local de Carmo se alimentó por tanto de productos procedentes de distintas provincias del Imperio Romano; desde los alfares italianos de Arezzo y Pisa, o los posteriores de La Graufesenque (en la Galia), Celti (Peñaflor), Tritium Magallum (La Rioja) o Los Villares de Andújar (Jaén), se traían los servicios domésticos de barniz rojo que adornaron las comidas de los carmonenses desde época augustea. Las mesas y habitaciones se iluminaron principalmente con lucernas producidas en talleres locales, y ya a partir del siglo II d. C, los alimentos se cocinaron y sirvieron en vajillas africanas.

L. De Ligt (1993: 15), que ha estudiado las características y el funcionamiento de las ferias y mercados en el Imperio Romano, presenta una distinción tripartita (local, regional, interregional) del fenómeno ferial en las sociedades pre-industriales, bajo los criterios de duración, área afectada, volumen de negocio y tipo dominante de transacción. La aplicación de la línea de trabajo de este investigador en una ciudad de la Bética como Carmo, situada en una comarca de la que probablemente era cabeza ${ }^{68}$, nos permite esbozar la presencia de una red de relaciones comerciales permanentes entre localidades ribereñas del Guadalquivir, Los Alcores y la Vega del Corbones ${ }^{69}$. Sin embargo la ausencia de referencias literarias y epigráficas respecto a la realización de ferias y mercados en la zona, precisa el que los estudios se centren sobre evidencias indirectas, análisis territoriales y datos arqueológicos que permiten despejar en parte la bruma que se cierne sobre este tipo de comercio en Carmo.

En dos trabajos recientes ${ }^{70}$ se ha examinado la periferia urbana de Carmo y los sistemas de organización y explotación de su territorio. La base analítica utilizada para precisar el espacio suburbano de la ciudad fue la segmentación de la zona sobre la base de los usos y funciones del suelo ${ }^{71}$. La cartografía viaria que se presentó muestra una dispersión de los asentamientos de primer orden,

67. Melchor (1999: 259) ha propuesto que desde los últimos decenios del s. I a. C., los minerales de Sierra Morena central y oriental se transportarían con bestias de carga hasta los diferentes puertos fluviales del Betis. En estos puertos, se cargarían en barcazas que los llevarían hasta Hispalis, en donde serían embarcados en grandes navíos con destino a Italia. Un mecanismo similar, pero en dirección contraria, es lo que debió producirse principalmente en la comercialización y distribución de estos productos menores, antes de poder ser adquiridos en Carmo u otros enclaves de los alrededores.

68. El análisis de los plomos monetiformes de Carmo, de fines del s. II a. C., mostraría que el área de influencia de Carmo alcanzaría una distancia de $40 \mathrm{~km}$ por la campiña, mientras que por los Alcores se extendería hasta el actual pueblo de El Viso (Casariego et al. 1987: 112 citado en Chic 2001a: 471), aunque recientemente se ha propuesto que la influencia se ejercería sobre un territorio mayor (Chic 2001a: 468). La desaparición de la ceca de Carmo nos ha privado de poder utilizar su área de distribución en el conocimiento de las relaciones comerciales que esta ciudad mantuvo con su entorno durante el Alto Imperio.

69. En palabras de McMullen (1970: 333-341), "ningún aspecto del comercio en el mundo romano ha sido más olvidado que el que implica el movimiento de bienes en cualquier radio dado de 15 millas; no obstante este comercio local debe representar al menos tres cuartas partes del valor de cambio en toda la economía en su conjunto".

70. Véase Amores 2001: 447-463 y Amores et al. 2001: 413-446.

71. Se definieron nueve puntos según las funciones del espacio suburbano 1. Elementos poliorcéticos 2. Infraestructuras: vías de comunicación 3. Infraestructuras: abastecimiento de aguas 4. Necrópolis 5. Edificios lúdicos 6. Áreas artesanales 7. Vertederos 8. Áreas residenciales 9. Explotaciones rurales (Amores 2001: 448).

ISSN: 1133-4525 ISSN-e: 2255-3924

SPAL 13 (2004)

http://dx.doi.org/10.12795/spal.2004.113.08 
que manifiesta la existencia de una vertebración económica del territorio, con ciudades ubicadas sobre el río Betis, principal vía de comercio del Bajo Guadalquivir, otras ubicadas en los alcores dominando las fértiles tierras de Los Alcores y La Vega, y otras sobre la propia Vega.

De la antigua Carmo, ciudad atravesada por la Vía Augusta, surgían diversos caminos públicos que la vinculaban con las localidades de Naeua, Canania, Arua, Axati, Oducia, El Gandul, Basilippo y $\mathrm{Vrso}^{72}$. A la calzada augusta, que desde Gades pasaba por Hispalis y Carmo en su camino hacia el Alto Guadalquivir ${ }^{73}$, le incumbió soportar un significativo trasiego de personas y mercaderías en su trayecto Hispalis / Carmo, tal y como manifiesta la importante necrópolis Oeste de Carmona $^{74}$. Este cementerio, cruzado por la vía Augusta en el denominado Camino del Quemadero, entre la necrópolis Oeste y el anfiteatro, para atravesar la ciudad por la Puerta de Sevilla (Corzo y Toscano 1992), muestra un índice de uso mucho mayor que el resto de áreas de enterramiento de la ciudad de Carmo. Este hecho, se encuentra directamente relacionado con el mayor movimiento de individuos por esta vía en dirección a la capital del conventus Hispalensis (Amores 2001).

En el tramo viario entre Carmo y Vrso, perpetuación de una antigua vía prerromana que pasaba por los asentamientos orientalizantes de Porcún y Montemolín, no existían ciudades romanas intermedias que permitiesen un contacto comercial en períodos cortos y permanentes ${ }^{75}$. Por lo que Vrso quedaba así un poco separada, pero no aislada de esta red de distribución, que debió de albergar un incesante tráfico de productos ${ }^{76}$.

La dada por falsa y hoy perdida inscripción de Ceres aparecida en Carmo y transmitida exclusivamente por C. M. Trigueros, al que se tachó de gran falsificador, es la única referencia epigráfica que muestra la existencia de una relación económica directa entre Carmo y diversas localidades

72. Las distancias entre Carmo y varias ciudades de su entorno (Canania: $17 \mathrm{~km}$; Arua: $17 \mathrm{~km}$; El Gandul: 21 km; Basilippo: 21 km; Naeua: 23 km; Oducia: 26 km; Obulcula: 30 km; Hispalis: $33 \mathrm{~km}$ ) nos muestra la densidad de núcleos de importancia que se encontraban en un radio de menos de $50 \mathrm{~km}$, entre los que tuvo que existir una compleja trama de ferias y mercados locales que, por medio del intercambio o la compra-venta, distribuían o adquirían los productos de importación que llegaban a los puertos fluviales del Guadalquivir. A estos mercados locales acudiría la población rural para la venta de sus excedentes y para la compra de los productos de semi-lujo que los arqueólogos encontramos en asentamientos rurales.

73. No debemos olvidar el dicho popular que nos recuerda "que todos los caminos conducen a Roma" tal y como indican los vasos de Vicarello para esta vía, que, a nuestro entender, debió jugar un papel ideológico y simbólico de gran importancia cuando fue proyectada y ejecutada durante el principado de Augusto. No debe ser un hecho casual que el punto de partida de la vía Augusta en Gades (desde el punto de vista de la Bética) sea el Océano Atlántico y que, atraviese bajo el templo augusteo situado sobre la Puerta de Sevilla en Carmo (Jiménez 1989), y salga por la también augustea Puerta de Córdoba (Ojeda 2001: 183), en dirección al Arco de Jano ubicado en la frontera de la Bética, y que a partir del año 2 a. C. se empleó para señalar el punto de origen de los miliarios de la provincia (Corzo y Toscano 1992). Por ello, no sería descabellado sopesar, la posibilidad de que en el templo augusteo de Carmo, hipotéticamente dedicado a Marte, se rindiera culto a Jano, entre cuyas advocaciones se encontraba la de dios de las puertas (Vázquez 2001).

74. Sobre la necrópolis oeste de Carmona, véase Bendala (1976).

75. Esta afirmación invalida la existencia de unas relaciones comerciales de compra-venta entre ambas ciudades en un sistema de ferias y mercados locales tal y como ha sido definido por L. De Ligt (1993: 15 y 51-54). Entre Carmo y Vrso debió de existir, sin embargo, un sistema de comercialización y distribución, basado en el fenómeno de ferias y mercados regionales, que se celebrarían amparadas seguramente en la celebración de festividades y eventos religiosos.

76. Los productos procedentes de los distritos mineros de Sierra Morena en este sector sevillano (Munigua), o de las canteras de mármol y arcilla de Peñaflor (Celti) quedaban conectadas por el río Guadalquivir y las ciudades de Arua, Canania o Naeua con la ciudad de Carmo. Se ha propuesto la posibilidad de que las placas de mármol coloreado que servían de pavimentación al entorno del foro de Carmo, que aparecieron en la intervención realizada en la Plaza da S. Fernando, procedieran de una cantera local en el entorno de Celti (Beltrán 2001: 149). A su vez, la presencia de "Cerámica de Imitación Tipo Peñaflor" documentada en Carmona desde el principado de Augusto (Román y Vázquez 2003 e.p.) indica la existencia de un comercio fluido entre Celti y Carmo que aparece reflejado en el registro a través de la cerámica y la piedra. 
del entorno ${ }^{77}$. En dicho epígrafe se nombra la relación entre los agrimensores de las ciudades de Carmo, Segobia, Hienipa, Arua, Oducia, Munigua, Axati y Obulco, lo que reflejaría que el contacto entre ellas debió de ser intenso y fluido. Aún así, falso o no, es más que probable que estas ciudades tuvieron un sistema de comercio y distribución de productos basado en las ferias locales denominadas nundinae y que se realizaban en cada ciudad cada siete u ocho días aproximadamente (De Ligt 1993: 51) al compartir vías directas o prácticamente directas entre sí.

Sabemos que el transporte terrestre durante el período romano era deficiente y que "los buhoneros eran, con sus acémilas cargadas de cacharros llamativos pero de poco valor, el único contacto importante con las ciudades" (Chic 2001b: 374), por lo que eran esenciales en la distribución de productos "menores" hacia los mercados locales, y más aún en una región como la que tratamos en este trabajo, que contaba con buenas vías fluviales y terrestres. La existencia de una amplia red de comunicaciones y la escasa distancia a la que se encontraban las ciudades de la zona, debieron de incidir de manera cuantitativa y rotativa en el comercio de mercaderías entre asentamientos, generando un importante trasiego de materiales y personas de un mercado local a otro.

Es evidente que las nundinae que se celebraran periódicamente en Carmo no serían el único medio que existiese a la hora de adquirir una pieza o un servicio de mesa regional o interprovincial. En Carmo debió haber lugares estables de venta, en los cuales entre diferentes productos se vendería cerámica de importación, aunque no poseemos ningún dato arqueológico sobre ello, salvo las propias cerámicas y la posible identificación de unas estructuras aparecidas en el entorno de la plaza de S. Fernando como tabernae, sin que se sepa el uso exacto que recibieron, aunque se han relacionado con el foro de la ciudad (Lineros y Domínguez 1985: 326-329; Beltrán 2001: 146).

Más importante resultan los eventos materializados en espectáculos, procesiones o días festivos, ya que sabemos que en torno a ellos se congregaban ferias y mercados de diversa duración (la duración vendría marcada por la del propio evento), que atraerían no sólo a individuos de la ciudad y su entorno rural más cercano, sino a personas y comerciantes procedentes de ciudades vecinas y alejadas, como si de un mercado regional o interregional se tratara. A este respecto, las fuentes nos han transmitido un relato de gran valor e importancia, pero que debe ser tomado con cierta cautela, a la hora de aplicar este testimonio documental a los datos que poseemos para Carmo. El martirio en la ciudad de Hispalis de las santas Justa y Rufina en el año 287 d. C. durante el principado de Diocleciano, se produce con reunión de la celebración de las festividades del dios Adonis tras un altercado en un mercado. El motivo del martirio fue la negativa de la santa Justa a colaborar en el evento entregando uno de los tiestos cerámicos que tenía a la venta, por lo que fue condenada y martirizada junto a Rufina ${ }^{78}$.

En el transcurso de la Intervención Arqueológica de Urgencia realizada en la C/ Pozo Nuevo 5 de Carmona (Belén et al. 1996), se documentó un pozo excavado en el alcor, que contenía un conjunto bastante unitario de cerámicas de mesa (campaniense tipo "Cales", T.S. Itálica y "Cerámica de Imitación Tipo Peñaflor"), macetas, cuencos de borde vuelto, fusayolas y dos piedras trabajadas, una triangular y otra en forma de fuste que han sido interpretadas como imágenes anicónicas de la divinidad (Belén et al. 1998). El estudio de los materiales, del contexto en que aparecieron y de su lectura simbólica llevaron a la identificación del conjunto como un testimonio de la

77. Stilow (2001: 96-99), en una reciente revisión de los epígrafes de Carmona, lo considera falso, advirtiendo que: "Cualquier inscripción transmitida únicamente por Trigueros debe a priori estar bajo sospecha y quienes se arriesguen a utilizarlas deberán primero probar su autenticidad". Su veracidad sin embargo ha sido defendida por G. Chic García (2001a) con base a la identificación en un "titulus pictus", documentado sobre un ánfora olearia del año 149 d. C. procedente de la Baetica, de una de las centurias (Agtes) que aparece nombrada en la inscripción y que Trigueros no podía conocer, y por lo tanto inventar.

78. Véase Riesco Chueca 1995.

ISSN: 1133-4525 ISSN-e: 2255-3924

SPAL 13 (2004)

http://dx.doi.org/10.12795/spal.2004.113.08 
existencia también de Adonias en la Carmo de época augustea / tiberiana. A pesar de la diferencia cronológica, si atendemos a la narración de lo acaecido en Hispalis, podríamos extrapolar la situación a la Carmo del cambio de Era e intuir que durante la celebración de éstas u otras festividades concurriría un mercado, quizás amparado en el propio evento, que surtiría a los participantes o espectadores de los productos que precisasen, ya fueran macetas, plantas, perfumes, animales, o cerámicas $^{79}$, como las documentadas en la Intervención Arqueológica de Urgencia efectuada en la calle Pozo Nuevo ${ }^{\circ} 5$ (Belén et al. 1996).

El conjunto de "Cerámicas de Imitación Tipo Peñaflor" documentado en Carmona supone un material básico para el conocimiento de los circuitos comerciales que enlazaron las distintas ciudades del entorno del río Betis durante el Alto Imperio. Un estudio exhaustivo de la distribución y del número de fragmentos documentados por yacimiento receptor permitiría llevar a cabo una discriminación de enclaves, al ser un tipo cerámico con una comercialización marcadamente provincial. Su estudio podría reflejar (especialmente para fines del s. I a. C y época Julio-Claudia / Flavia) unas pautas de contactos no esporádicos y entendibles como comercio periódico entre yacimientos, en el cual se mezclarían piezas de procedencia regional, con piezas de producción foránea destinadas a un mismo fin: comercio y consumo ${ }^{80}$.

\section{FUENTES}

CORPUS DE INSCRIPCIONES LATINA DE ANDALUCÍA. (González Fernández, J.): Volumen II: Sevilla, Tomo I. La Vega (Hispalis), Consejería de Cultura y Medio Ambiente de la Junta de Andalucía, Dirección General de Bienes Culturales, Sevilla, 1991.

CÉSAR.: Guerra Civil, Biblioteca Clásica de Gredos (trad. Calonge Ruiz, J.), Gredos, Madrid, 1986. ESTRABÓN.: Geografía, Biblioteca Clásica de Gredos (trad. Meana, M. J.), Gredos, Madrid, 1998. MARCIAL.: Epigramas, Biblioteca Clásica de Gredos (trad. Fernández Valverde, J. y Ramírez de Verger, A.), Gredos, Madrid, 1997.

\section{BIBLIOGRAFÍA}

ALARÇAO, A. M. (1975): "Les sigillées italiques”, Fuilles de Conimbriga, IV: 3-66, París Difusión, E. de Boccard, París.

AMORES, F. (2001): "Entre campo y ciudad. La periferia urbana en Carmo", Carmona Romana, Actas del II Congreso de Carmona (Caballos Rufino, A., Ed.): 447-463, Universidad de Sevilla, Sevilla.

AMORES, F. y FERNÁNDEZ CANTOS, A. (2000): "La necrópolis de La Cruz del Negro", Argantonio rey de Tartessos (Aranegui, C. Ed.): 157-163, Fundación El Monte, Sevilla.

79. En Marcial podemos encontrar a través de sus epigramas numerosas referencias sobre la festividad de las Saturnales en Roma y la costumbre de intercambiar regalos de diversa índole (p.e. II 85; IV 46; IV 88; V 19; V 30; V 84; VII 53; VII 91; X 29; XI 6; XIV 1 y XIV 71). Como nos transmite el autor, muchos echan mano de lo que no quieren y sobra en sus casas, mientras que un poeta como él regala durante esas celebraciones sus propios escritos y vasos de barro (V 18 y 59) que posiblemente adquiría en la Subura (VII 31).

80. La existencia en el valle del Betis de mercaderes itinerantes, que vivían de su continuo movimiento de un asentamiento a otro ofreciendo productos procedentes de todo el Imperio Romano, ha sido eclipsado por la importancia del comercio fluvial y marítimo a gran escala que se encontraba protagonizado principalmente por intereses estatales y annonarios. 
AMORES, F. y KEAY, S. J. (1999): "Las Sigillatas de Imitación Tipo Peñaflor o una serie de Hispánicas Precoces", Terra Sigillata Hispánica: Centros de fabricación y producciones altoimperiales: 235-252, Universidad de Jaén / Universidad de Málaga, Málaga.

AMORES, F. et al. (2001): "La organización y explotación del territorio de Carmo", Carmona Romana, Actas del II Congreso de Carmona (CABALLOS RUFINO, A., Ed.): 413-446, Universidad de Sevilla, Sevilla.

BELÉN, M. (1983): "Aportaciones al conocimiento de los rituales funerarios en la necrópolis romana de Carmona", Homenaje al Prof. Martín Almagro Basch Vol. III: 209-226, Ministerio de Cultura, Madrid.

BELÉN, M. y LINEROS, R. (2001): "15 años de arqueología en Carmona", Carmona Romana, Actas del II Congreso de Carmona (CABALLOS RUFINO, A., Ed.): 109-134, Universidad de Sevilla, Sevilla.

BELÉN, M. et al. (1996): "Excavaciones en Carmona (Sevilla). Las Termas de la Calle Pozo nuevo", Anuario Arqueológico de Andalucía III: 630-639.

BELÉN, M. et al. (1997): Excavaciones en la Casa-Palacio del Marqués de Saltillo, Consejería de Cultura, Sevilla.

BELÉN, M. et al. (1998): "Cultos betílicos en Carmona romana" Actas del Congreso Internacional GIREA-ARYS VII; Divinas Dependencias. Individuos, Santuarios, Comunidades, Universidad de Huelva.

BELTRÁN, J. (2001): "Arqueología de la Carmona romana: el esquema urbano", Carmona Romana, Actas del II Congreso de Carmona (CABALlOS RUFINO, A., Ed.): 135-158, Universidad de Sevilla, Sevilla.

BELTRÁN, M. (1990): Guía de la cerámica romana. Tipología y clasificación, Libros Pórtico, Zaragoza.

BENDALA GALÁN, M. (1976): La necrópolis romana de Carmona (Sevilla), Diputación Provincial de Sevilla, Sevilla.

BÉMONT, C. (1976): Recherches méthodologiques sur la céramique sigillée. Les vases estampillées de Glanum. Bibliothèque des Ecole Francaises d'Athènes et de Rome 227, École Francaise de Rome, Roma.

BÉMONT, C. y BOURGEOIS, A. (1986): "Le noms des potiers", La terra sigillata gallo-romaine, Lieux de production du Haut-Empire (BEMONT, C. y JACOB, J. P., Eds.): 277-286, París.

BÉMONT, C. y JACOB, J. P. (Eds.) (1986): La terra sigillata gallo-romaine. Lieux de production du Haut-Empire, Éditions de la Maison des Sciences de 1'Homme, París.

BOUBÉ (1965): Terra sigillata hispanique en Maurétanie Tingitane, I : Marques de potiers, Études et Travaux d'Archéologie Marocaine, Rabat.

BOURGEOIS, A y MAYET, F. (1991): Les sigillées. Fouilles de Belo. Belo VI. Col. de la Casa de Velázquez, Archéologie XIV, Casa de Velázquez, Madrid.

CABALLOS, A. (1986): "La romanización de las ciudades de la Bética y el surgimiento de senadores provinciales", Revista de Estudios Andaluces 6: 13-26.

CABALLOS, A. (1990): Los senadores hispanorromanos y la romanización de Hispania (siglos I-III), I. Prosopogragrafía, Gráficas Sol, Écija.

CABALLOS, A. (2001): "La paulatina integración de Carmo en la Romanidad", Carmona Romana, Actas del II Congreso de Carmona (CABALLOS RUFINO, A., Ed.) : 3-17, Universidad de Sevilla, Sevilla.

CASTELLANO, J. J. (2000): "La Terra Sigillata sudgálica del área del anfiteatro romano de Carthago Nova", Saguntum 32: 151-167.

CHIC, G. (1985): Epigrafía anfórica de la Bética I: Las marcas impresas en el barro sobre ánforas olearias (Dressel 19, 20 y 23), Universidad de Sevilla, Departamento de Historia Antigua, Sevilla.

ISSN: 1133-4525 ISSN-e: 2255-3924

SPAL 13 (2004)

http://dx.doi.org/10.12795/spal.2004.i13.08 
CHIC, G. (1987): Epigrafía anfórica de la Bética II: Los rótulos pintados sobre ánforas olearias, Universidad de Sevilla, Departamento de Historia Antigua, Sevilla.

CHIC, G. (1990): La navegación por el Guadalquivir entre Córdoba y Sevilla en época romana, Gráficas Sol, Écija.

CHIC, G. (1997): Historia económica de la Bética en la época de Augusto, Padilla Libros, Sevilla.

CHIC, G. (2001a): "Religión, territorio y economía en la Carmo romana", Carmona Romana, Actas del II Congreso de Carmona (CABALLOS RUFINO, A., Ed.): 465-476, Universidad de Sevilla, Sevilla.

CHIC, G. (2001b): "Comercio y comerciantes en la Málaga republicana y altoimperial”, Comercio y comerciantes en la Historia Antigua de Málaga (s. VIII a. C.-año 711 d. C.) Actas del II Congreso de Historia Antigua de Málaga (WULFF, F.; CRUZ, G. y MARTÍNEZ, C., Eds): 351-384, Diputación de Málaga, Málaga.

COLLS, D et al. (1977): "L'épave Port-Vendres II et le commerce de la Bétique à l'époque de Claude", Archaeonautica 1.

CONLIN, E. (2003): "Los inicios del III milenio a. C. en Carmona: las evidencias arqueológicas", CAREL año I núm. 1: 83-144.

CORZO, R y TOSCANO, M. (1992): Las vías romanas de Andalucía, Consejería de Obras Publicas y Transportes, Sevilla.

DE LIGT, L. (1993): Fairs and Markets in the Roman Empire, J. C. Cieber, Amsterdam.

ESCRIVÁ TORRES, V. (1989): Cerámica romana de Valentia: la Terra Sigillata Hispánica, Serie Arqueológica Municipal 8, Valencia, Ajuntament de Valencia.

ESCRIVÁ TORRES, V. (1991): La Terra Sigillata Hispánica de Valentia, Ajuntament de Valencia, Valencia.

ETTLINGER, E. et al. (1990): Conspectus Formarum Terrae Sigillatae Italico Modo Confectae, Bonn, Rudolf Hubelt.

FERNÁNDEZ GARCÍA, M. I. (1987): "Las primeras generaciones de alfareros del centro de producción de Los Villares de Andújar, Jaén”, Actes Jornades Internacionals dÁrqueología Romana: 482-489, Granollers.

FERNÁNDEZ GARCÍA, M. I. (1998): “Características de la Sigillata fabricada en Andújar", Terra Sigillata Hispánica: estado actual de la investigación (Fernández García, M. I., Ed) : 49-104, Universidad de Jaén, Baeza.

FINLEY, M. I. (1975): La economía de la antigüedad, Fondo Cultura Económica, México-MadridBuenos Aires.

GARABITO, T y SOLOVERA, M. E. (1976): “Terra sigillata hispánica de Tricio, II. Marcas de alfarero". Studia Archaeologica, 40, Universidad de Valladolid, Departamento de Prehistoria y Arqueología, Valladolid.

GARABITO GOMEZ, T. (1978): Los alfares romanos riojanos. Producción y comercialización. Biblioteca Praehistorica Hispana XVI, CSIC, Madrid.

GOUDINEAU, Ch. (1968): La céramique aretine lisse (fouilles de l'École Française de Rome à Bolsena (Poggio Moscini) 1962-1967. Mélanges d’Archéologie et d’Historie, Supp. 6, París.

JIMÉNEZ, A. (1989): La Puerta de Sevilla, Consejería de Obras Publicas y Transportes, Málaga.

LINEROS, R. y DOMÍNGUEZ, F. (1985): "Excavaciones arqueológicas de urgencia en Carmona (Sevilla)", Anuario Arqueológico de Andalucía III: 326-329.

MARTÍNEZ RODRÍGUEZ, F. (1989): "Las cerámicas béticas de imitación tipo Peñaflor: bases para el estudio de un nuevo grupo cerámico de época altoimperial”, Boletín de la Asociacion de Amigos de la Arqueología 26: 60-65. 
MÁRQUEZ MORENO, C. (2001): "La ornamentación arquitectónica de la Carmona romana", Carmona Romana, Actas del II Congreso de Carmona (CABALLOS RUFINO, A., Ed.): 251262, Universidad de Sevilla, Sevilla.

MAYET, F. (1970): “Á propos de deux potiers de Mérida: Valerius Paternus et Lapillius”, Mélanges de la Casa de Velázquez VI.

MAYET, F. (1984): Les Céramiques sigillées hispaniques. Contribution à l histoire économique de la Péninsule Ibérique sous l'Empire romain, 2 vols., Centre Pierre París, París.

MCMULLEN, R. (1970): "Market-Days in the Roman Empire", Phoenix XXIV, 4.

MELCHOR, E. (1999): "Contactos comerciales durante el Alto Imperio", Habis 30: 253-269.

MEZQUÍRIZ DE CATALÁN, M. A. (1961): Terra Sigillata Hispánica, 2 Vols., Doménech, Valencia.

MEZQUÍRIZ DE CATALÁN, M. A. (1985): "Terra Sigillata Ispánica", Enciclopedia dell'Arte Antica Classica ed Orientale. Atlante delle Forme Ceramiche. II: 97-174, Istituto della Enciclopedia Italiana, Roma.

MONTESINOS I MARTÍNEZ, J. (1998): Comercialización de Terra Sigillata en Ilici, Real Academia de Cultura Valenciana. Sección de Prehistoria y Arqueología; Serie Arqueológica 16, Valencia.

OJEDA, R. (2001): "Nuevos datos sobre la "Puerta de Córdoba" en época romana", Carmona Romana, Actas del II Congreso de Carmona (CABALLOS RUFINO, A., Ed.): 159-187, Universidad de Sevilla, Sevilla.

ORDÓÑEZ AGULLA, S. (1998): Primeros pasos de la Sevilla romana ( siglos I a. C.-I d.C.), Biblioteca de temas sevillanos, Ayuntamiento de Sevilla, Sevilla.

OSWALD, F. (1931 [reed. 1983]): Index of Potters Stamps on Terra Sigillata “Samian Ware”, Avignon Revue Archeologique Sites, Margidunum.

OSWALD, F. y PRICE, T.D. (1920 [reed 1984]): An introduction to the study of terra sigillata, Longmans, Green and Co. Londres.

OXE, A. (1968): Corpus Vasorum Arretinorum, (COMFORT, H., Ed.), Rudolf Habelt, Bonn.

PÉREZ OUTERIÑO, B. (1990): Sellos de alfarero en Terra Sigillata Itálica encontrados en Mérida, Cuadernos Emeritenses 3, Mérida.

POVEDA NAVARRO, A. y RIBERA LACOMBA, A. (1985): "Marcas de Terra Sigillata de Elda", Saguntum 19: 301-310.

PUCCI, G. (1973): "La produzione della cerámica aretina. Note sull' "industria" nella prima età imperiale romana", Darrch., VI: 255-293.

PUCCI, G. (1985): "Terra Sigillata Itálica”, Enciclopedia dell'Arte Antica Clásica e Orientale. Atlante delle Forme Ceramiche. II: 359-405, Istituto della Enciclopedia Italiana, Roma.

REMESAL, J. (1986): La annona militaris y la exportación de aceite bético a Germania, Universidad Complutense de Madrid, Madrid.

RIBERA LACOMBA, A. (1981): "Las marcas en Terra Sigillata de Valentia", Saguntum 16: 209-246.

RIESCO CHUECA, P. (1995): Pasionario hispánico, Universidad de Sevilla, Secretariado de Publicaciones, Sevilla.

ROCA ROUMENS, M. (1976): Sigillata Hispánica producida en Andújar, Patronato José María Quadrado, Jaén.

ROCA ROUMENS, M. (1978): "Algunas consideraciones en torno a las influencias itálicas en la sigillata hispánica", Cuadernos de Prehistoria de la Universidad de Granada 3: 285-302, Granada.

ROCA ROUMENS, M. (1991): "Producción y comercialización de la sigillata producida en la Bética", La Bética en su problemática histórica, (ROCA, M. y FERNÁNDEZ, M. I., Ed.): 221235, Universidad de Granada. Granada.

ISSN: 1133-4525 ISSN-e: 2255-3924

SPAL 13 (2004)

http://dx.doi.org/10.12795/spal.2004.113.08 
ROMÁN, J. M. (2001): "El almacenamiento de grano en Carmona: el horreum de San Blas", Carmona Romana, Actas del II Congreso de Historia de Carmona (CABALLOS RUFINO, A., Ed.) : 233-250, Universidad de Sevilla, Sevilla.

ROMÁN, J. M. y VÁZQUEZ, J. (2003): "I.A.U en el solar n 2 de la calle Calatrava de Carmona (Sevilla)", Anuario Arqueológico de Andalucía, (e.p.).

SÁENZ, M. P. y SÁENZ, C. (1999): "Estado de la cuestión de los alfares riojanos. La Terra Sigillata Hispánica altoimperial", Terra Sigillata Hispánica: Centros de fabricación y producciones altoimperiales (ROCA ROUMENS, M. y FERNÁNDEZ GARCÍA, M. I. Coords): 61-136, Universidad de Jaén/ Universidad de Málaga, Málaga.

SÁNCHEZ-LA FUENTE PÉREZ, J. (1985): Comercio de cerámicas romanas en Valeria, Diputación provincial de Cuenca, Cuenca.

SERRANO RAMOS, E. (1983): "Dispersión de la Sigillata Hispánica fabricada en los talleres de la Bética”, Boletín del Museo Arqueológico Nacional, I-2: 151-157.

SERRANO RAMOS, E. (1991): Terra Sigillata de los alfares de Singilia Barba, Universidad de Málaga, Málaga.

SERRANO RAMOS, E. (1997): "La producción cerámica de los talleres romanos de la depresión de Antequera”, Figlinae Malacitanae. La producción de cerámica romana en los territorios malacitanos, Universidad de Málaga, Málaga.

SERRANO RAMOS, E. (1999): "Producciones hispánicas precoces", Terra Sigillata Hispánica: Centros de fabricación y producciones altoimperiales: 231-233, Universidad de Jaén / Universidad de Málaga, Málaga.

SILLIÈRES, P. (1990): Les voies de communication de l'Hispanie meridionale, E. De Boccard, París.

SOTOMAYOR, M. (1972): "Andújar, centro de producción y exportación de sigillata a Mauritania”, Noticiario Arqueológico Histórico. Arqueología 1: 263-289.

SOTOMAYOR, M. (1998): "Los Villares de Andújar. Historia de la investigación”, Terra Sigillata Hispánica: estado actual de la investigación (FERNÁNDEZ GARCÍA, M. I., Ed): 31-48, Universidad de Jaén, Baeza.

SOTOMAYOR, M.; ROCA, M. y FERNÁNDEZ, Ma. I. (1999): "Centro de producción de Los Villares de Andújar (Jaén)", Terra Sigillata Hispánica: Centros de fabricación y producciones altoimperiales: 19-60, Universidad de Jaén / Universidad de Málaga, Málaga.

STYLOW, A. (2001): "Una aproximación a la Carmo romana a través de su epigrafía. Nuevas aportaciones y revisión crítica", Carmona Romana, Actas del II Congreso de Historia de Carmona (CABALLOS RUFINO, A., Ed.): 95-105, Universidad de Sevilla, Sevilla.

TABALES, M. A. (2001): "Algunas aportaciones arqueológicas para el conocimiento urbano de Hispalis", Habis 32: 387-423.

TABALES, M. A. y JIMÉNEZ, A. (2001): "Hallazgo de una nueva inscripción referente al cuerpo de olearios en el Alcázar de Sevilla", Habis 32: 375-385.

VÁZQUEZ, J. (2001): "Carmona, un enclave fortificado del Bajo Guadalquivir", Actas del Congreso Internacional de fortificaciones en el entorno del Bajo Guadalquivir : 179-188, Ayuntamiento de Alcalá de Guadaíra, Alcalá de Guadaíra.

VÁZQUEZ, J. (2002): "Marcas de alfarero sobre Terra Sigillata procedente de la antigua Carmo" SPAL 11: 377-389.

VÁZQUEZ, J.; GARCÍA FERNÁNDEZ, F. J. y GONZÁLEZ PARRILLA, J. M. (e.p.): “Consideraciones en torno a las Cerámicas de Imitación "Tipo Peñaflor" documentadas en la necrópolis romana de la calle Bellidos (Écija, Sevilla)", Spal 14. 
VENTURA, J. J. (1990): La cerámica Campaniense en Andalucía Occidental, Tesis Doctoral, Universidad de Sevilla, inédita.

VENTURA, J. J. (2001): "Cerámicas de barniz negro en Carmona", Carmona Romana, Actas del II Congreso de Historia de Carmona (CABALLOS RUFINO, A., Ed.): 321-337, Universidad de Sevilla, Sevilla.

VERNHET, A. (1986): "Centre de production de Millau. Atelier de La Graufesenque" La terra sigillata gallo-romaine, Lieux de production du Haut-Empire (BEMONT, C. y JACOB, J. P., Eds.): 96-103, Éditions de la Maison des Sciences de 1'Homme, París.

WELLS, C. M. (1977): "L'Implantation des ateliers de céramique sigillée en Gaule: Problematique de la Recherche", Figlina 2: 1-11. 

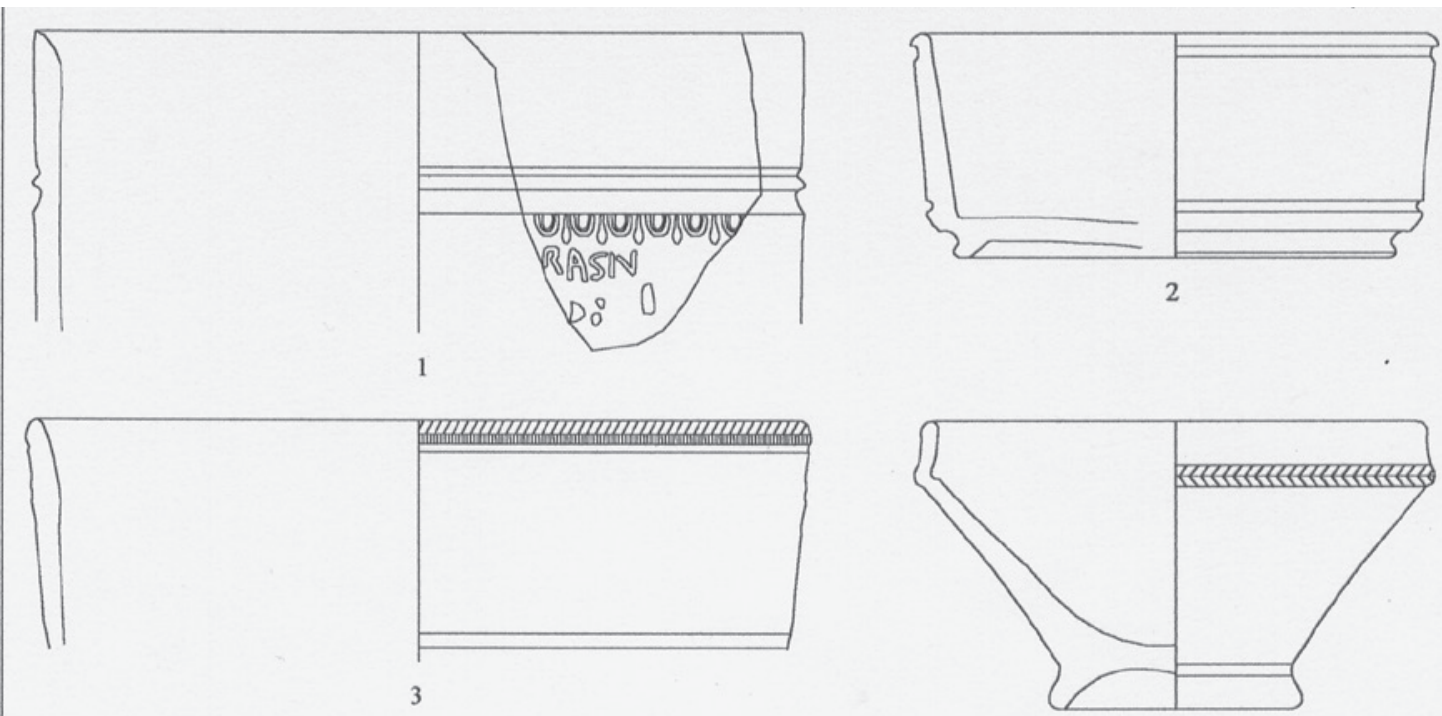

4
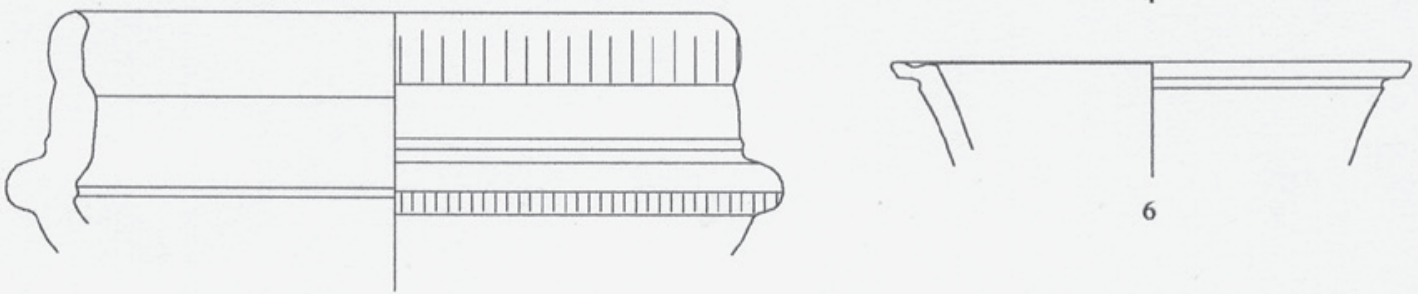

5
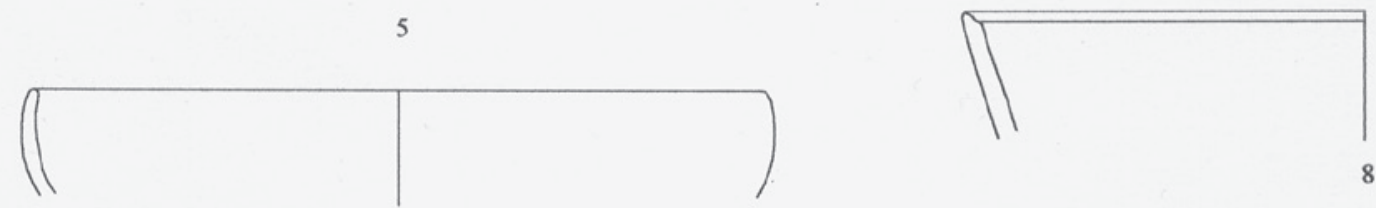

7
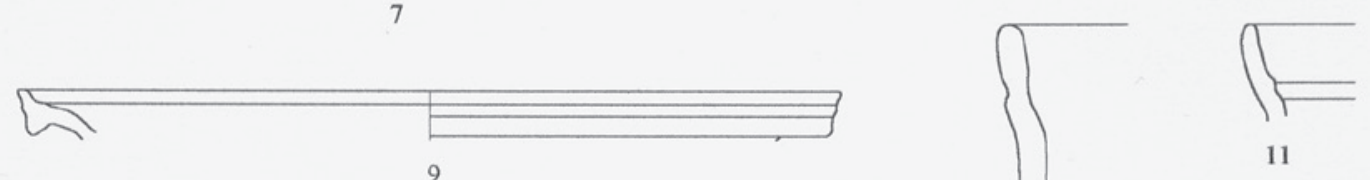

10
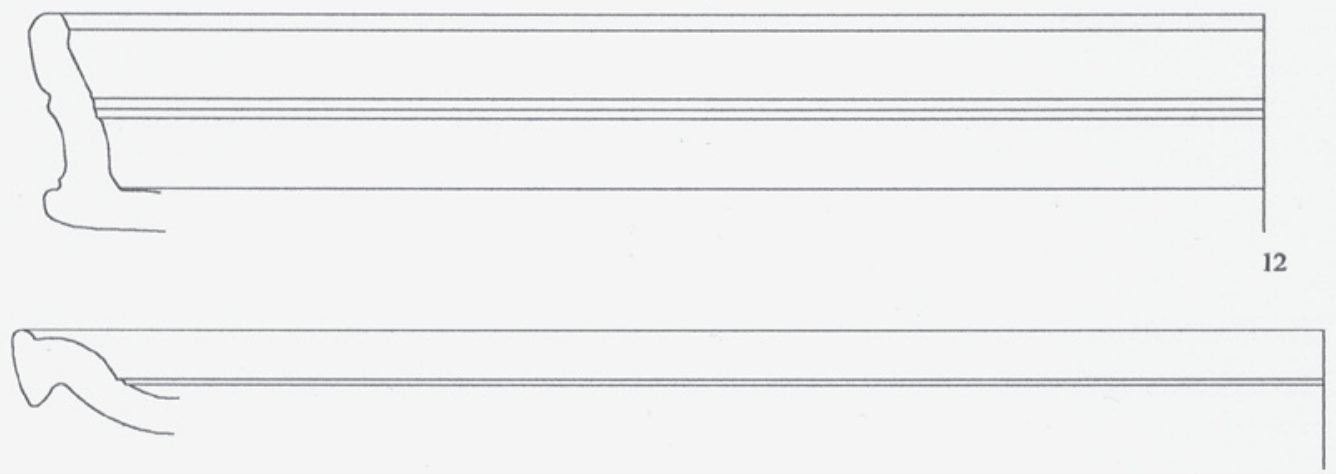

Figura 1. T.S.I. Formas documentadas en Carmo

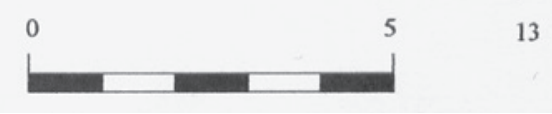



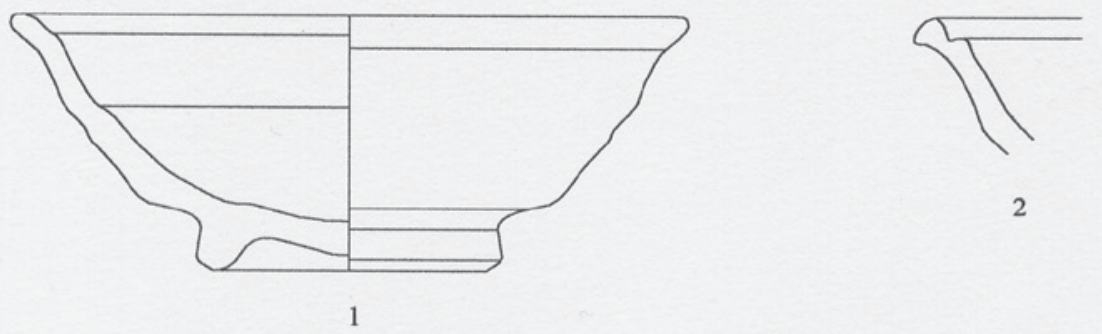

2

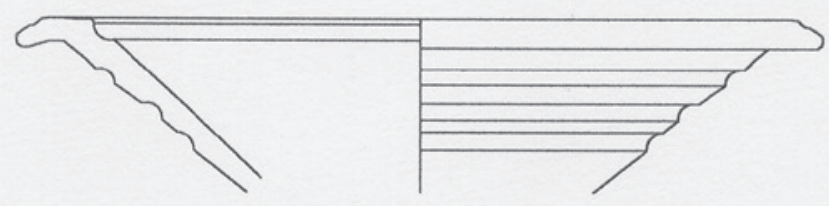

3
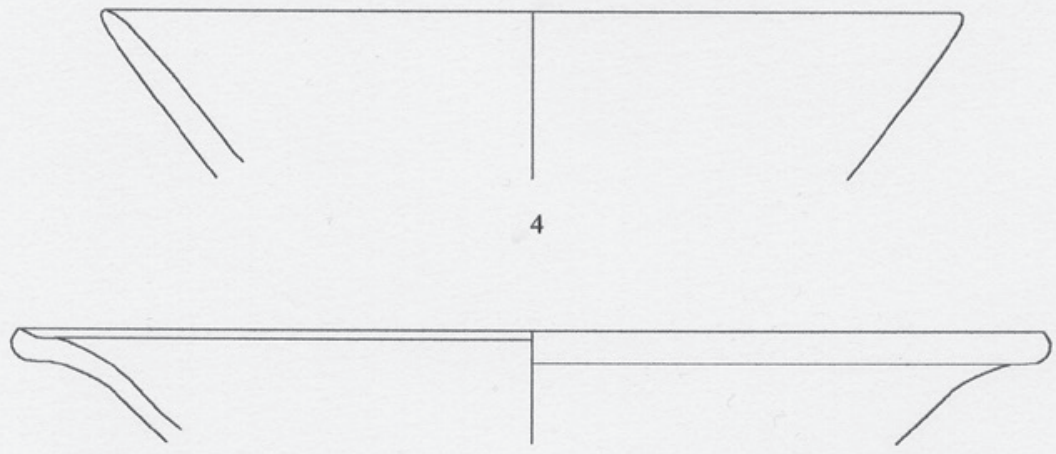

5

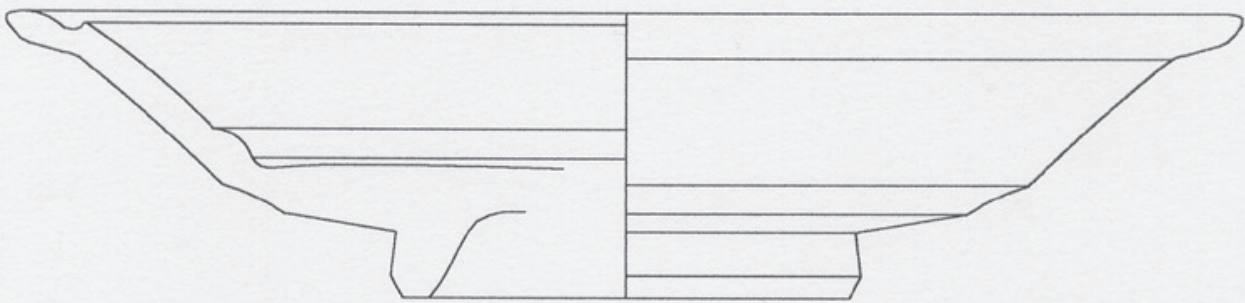

6

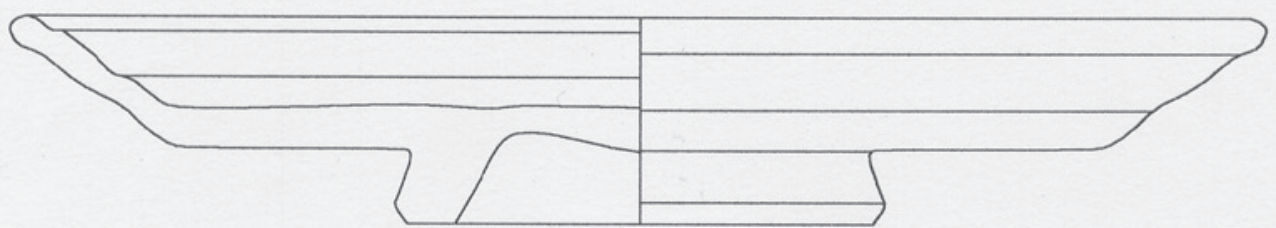

7

Figura 2. "T.S. de Imitación Tipo Peñaflor". Formas documentadas.

ISSN: 1133-4525 ISSN-e: 2255-3924

SPAL 13 (2004)

http://dx.doi.org/10.12795/spal.2004.i13.08 

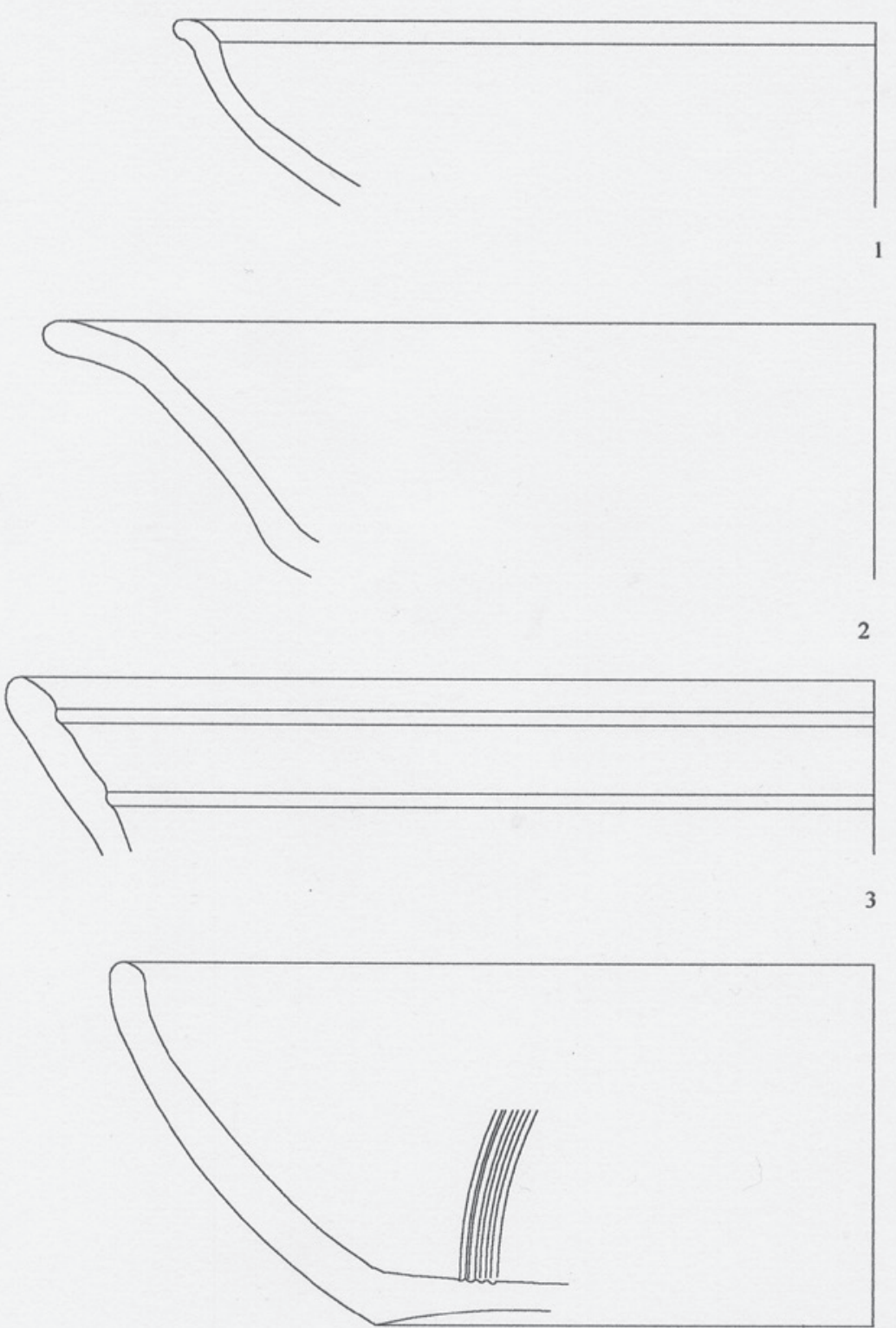

4

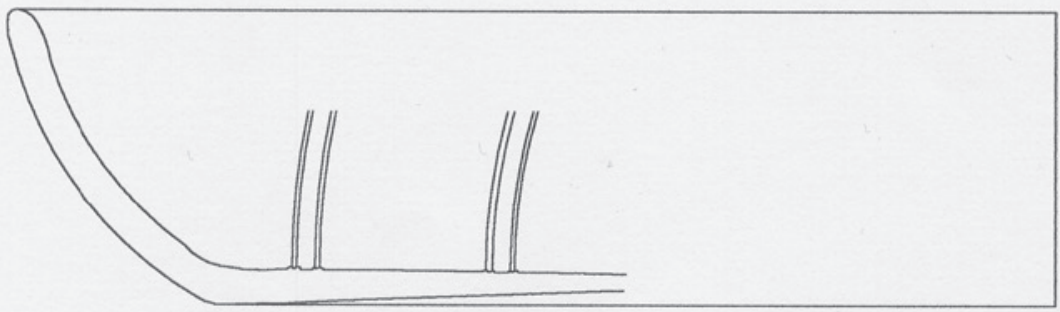

Figura 3. "Ceramicas de imitación Tipo Peñaflor". Formas documentadas. 


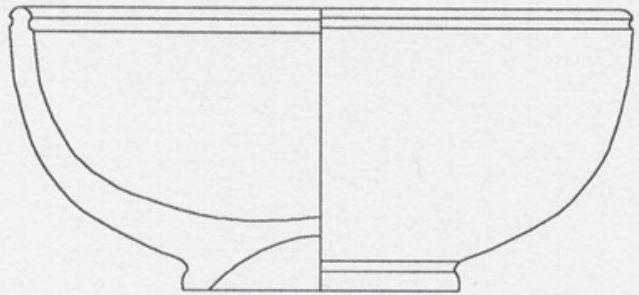

1

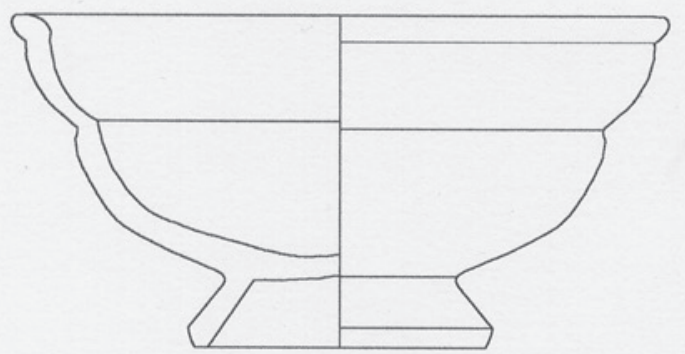

3
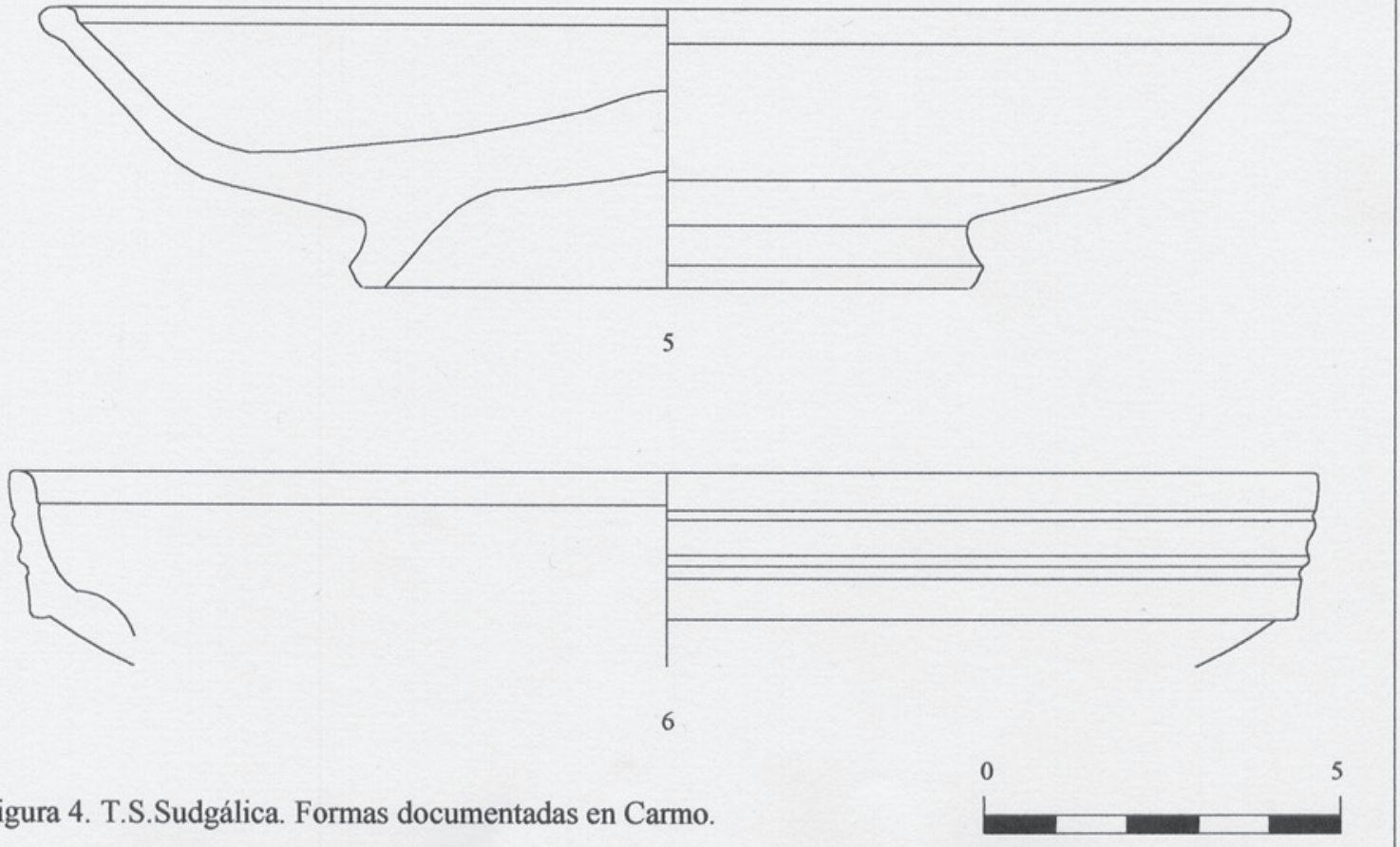

ISSN: 1133-4525 ISSN-e: 2255-3924

http://dx.doi.org/10.12795/spal.2004.i13.08

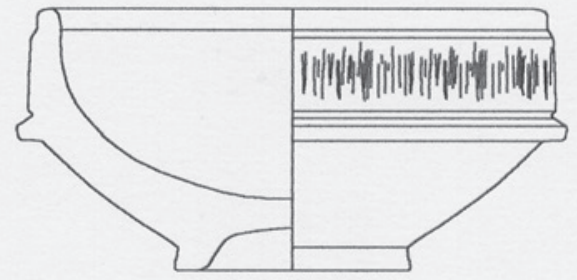

2

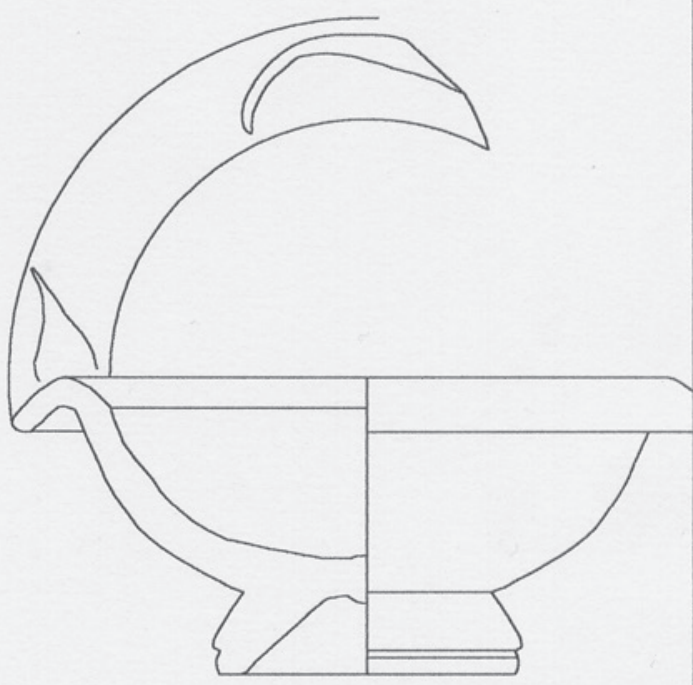

4
Figura 4. T.S.Sudgálica. Formas documentadas en Carmo. 

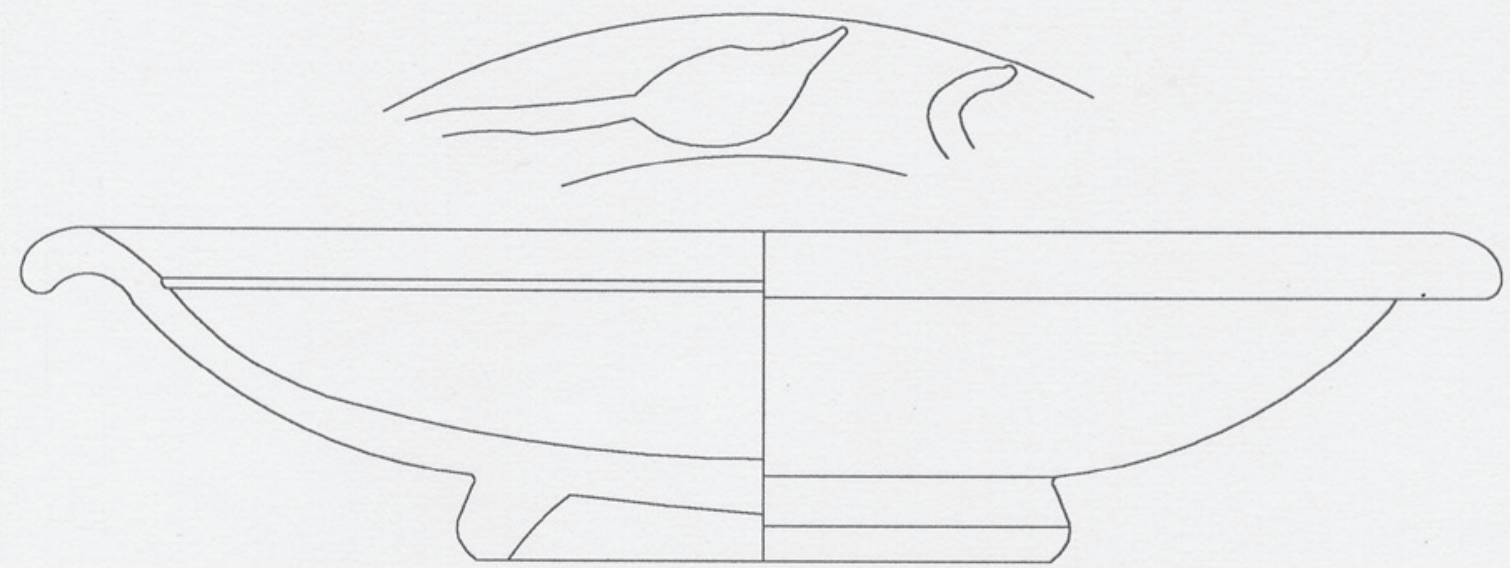

1

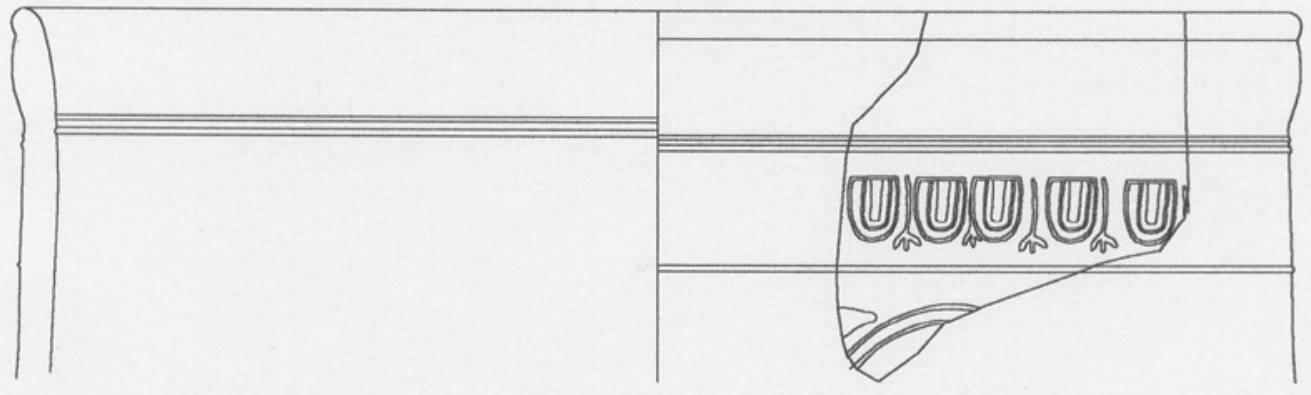

2

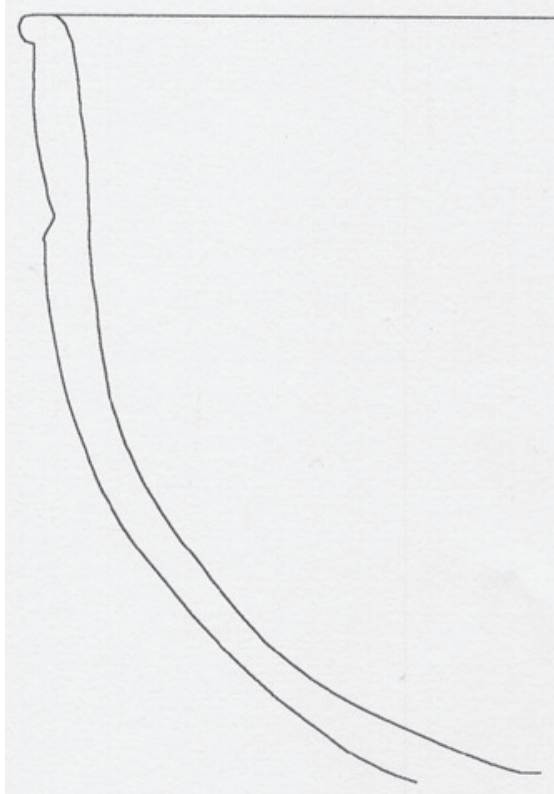

Figura 5. T.S.Sudgálica. Formas documentadas en Carmo. 

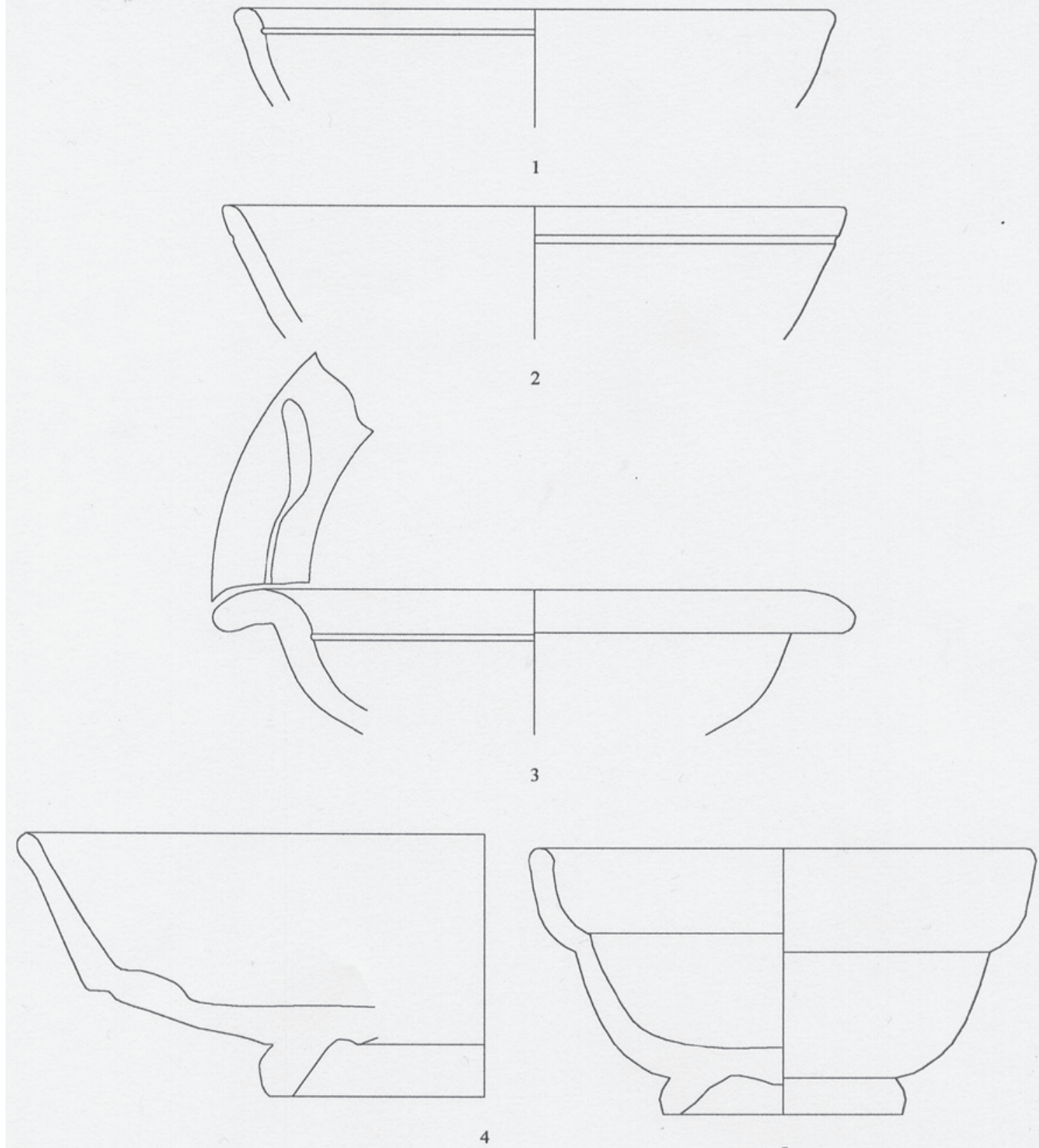

5
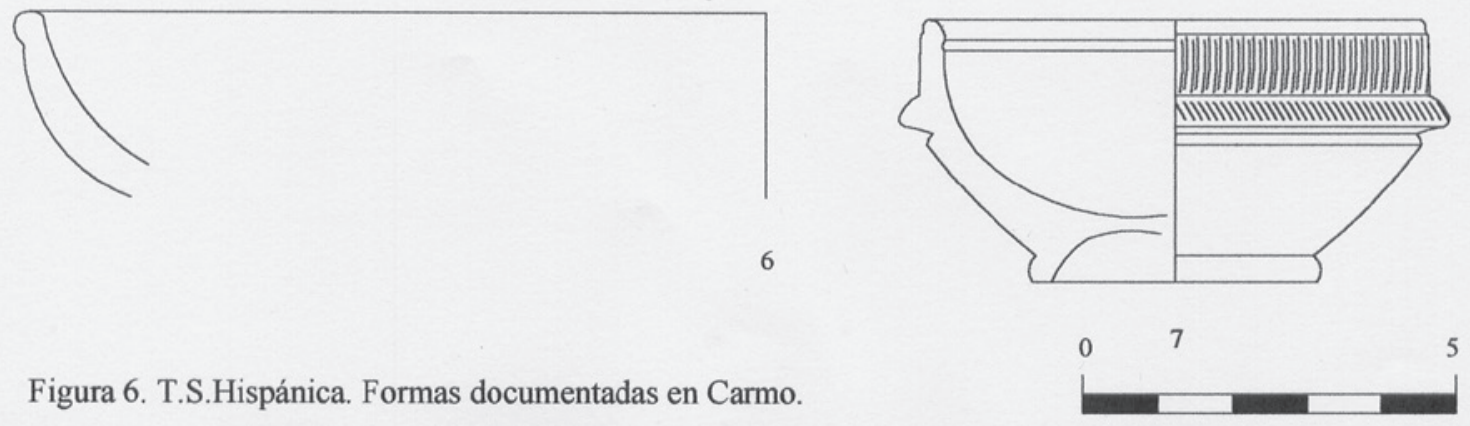

Figura 6. T.S.Hispánica. Formas documentadas en Carmo.

ISSN: 1133-4525 ISSN-e: 2255-3924

SPAL 13 (2004)

http://dx.doi.org/10.12795/spal.2004.i13.08 


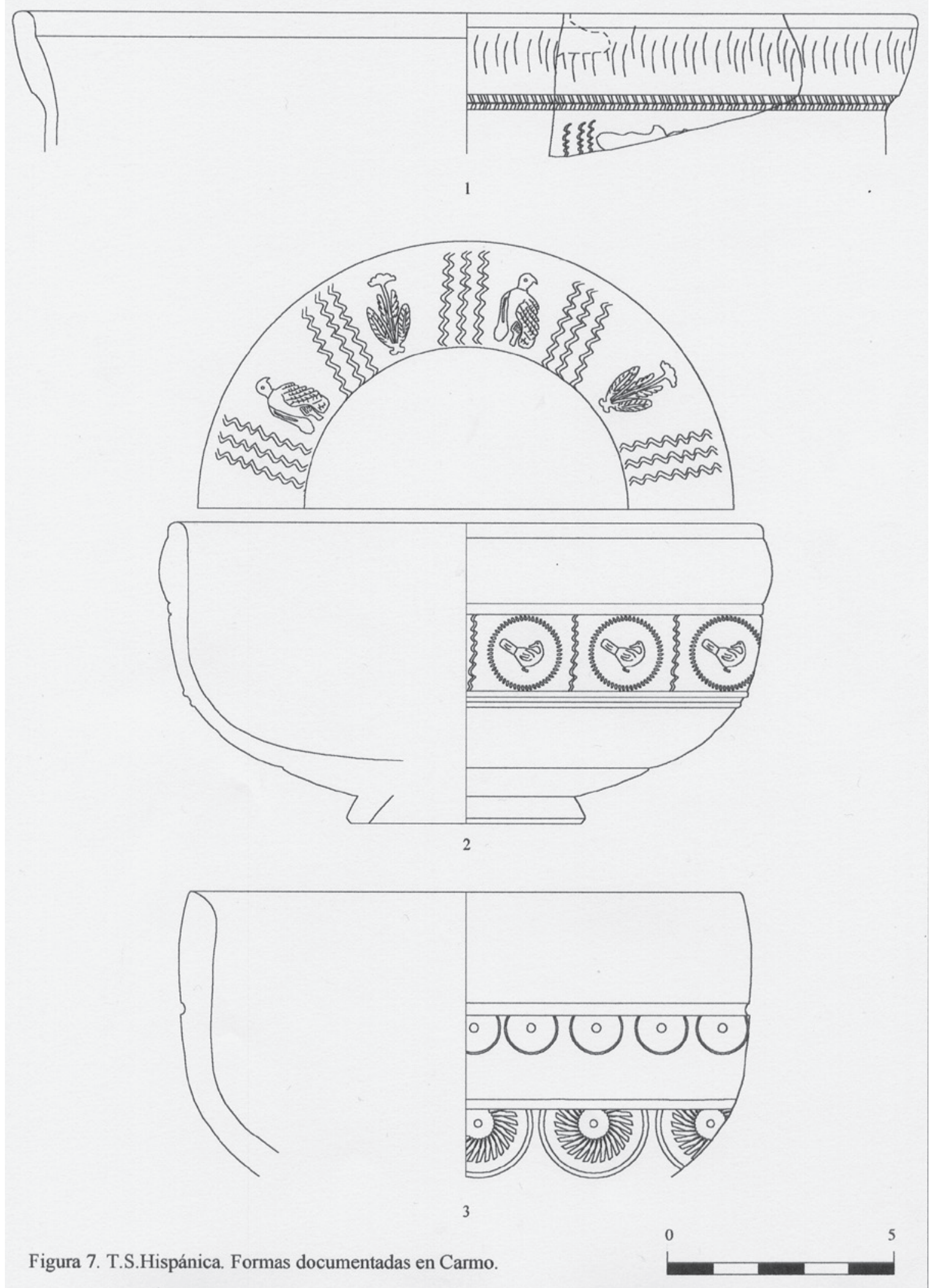

